\section{La investigación como valor social de la Universidad, el caso del SUE}

UTE. Revista de Ciències de l'Educació

Monogràfic 2018. Pàg. 45-67

ISSN 1135-1438. EISSN 2385-4731

http://revistes.publicacionsurv.cat/index.php/ute

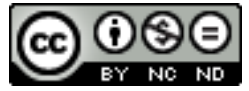

DOI: https://doi.org/10.17345/ute.2017.3.1939

Federico Gutiérrez-Solana Salcedo
Director del Centro Internacional Santander Emprendimiento - CISE

Rebut: 12/09/2017 Acceptat: 13/10/2017

\title{
Resumen
}

Este trabajo analiza la investigación del SUE como valor social, consideradas las universidades como bien público. Esto exige valorar sus resultados de generación de conocimiento, la inversión realizada para ello, y los resultados de innovación y competitividad alcanzados, como consecuencia de su transferibilidad, en el sistema relacional universidad-entorno social.

Toda esta cadena relacional se compara con las situaciones de aquellos países top en calidad y cantidad de sus resultados de investigación con el fin de conocer aquellas situaciones más eficaces que deben servir de referencia a la hora de planificar el caso español. La planificación estratégica de la investigación española requiere universidades-investigadoras-emprendedoras proactivas en reforzar la cultura de la transferencia de conocimiento.

Se concluye vinculando toda la estrategia de la función investigadora universitaria a un modelo sencillo de crecimiento social basado en gestionar el conocimiento en torno a tres grandes ejes: 1 Generación de Conocimiento (1 Investigación); 2 Transferencia del Conocimiento, y 3 Aplicación Productiva del Conocimiento (2-3 Innovación). Las universidades deben responsabilizarse de hacer lo necesario para que esto se produzca.

Palabras clave: Investigación, SUE, innovación, transferencia, competitividad, bien social, crecimiento social.

\begin{abstract}
This paper analyzes SUE research as a social value, considering universities as a public good. This requires assessing the results of knowledge generation, the investment made for it, and the results of innovation and competitiveness achieved, as a consequence of its transferability, in the university-social environment relational system.

All this relational chain is compared with the situations of those top countries in quality and quantity of their research results in order to know the most effective situations that should serve as reference when planning the Spanish case. The strategic planning of Spanish research requires proactive university-researchers-entrepreneurs to reinforce the culture of knowledge transfer.

It is concluded by linking the whole strategy of the university research function to a simple model of social growth based on managing knowledge around three main areas: 1 Knowledge Generation (1 Research); 2 Transfer of Knowledge, and 3 Productive Application of Knowledge (23 Innovation). Universities should be responsible for doing what is necessary for this to occur.
\end{abstract}

Key words: Research, SUE, innovation, transfer, competitiveness, social good, social growth. 


\section{Introducción}

El valor social de cualquier actividad debe establecerse por comparación entre los resultados de la misma y lo que estos representan para la sociedad en su conjunto, no exclusivamente para los responsables de ejecutarla, y, con preferencia, en su entorno más próximo.

La relación que así se establece entre universidades y entornos, por la funcionalidad de las primeras, es reflexiva estableciendo un círculo virtuoso. Las sociedades demandan funcionalidad a las universidades y contribuyen a su financiación y estas devuelven a la sociedad los resultados de su actividad, de forma que si éstos tienen valor es porque generan crecimiento con el que la sociedad incrementa sus capacidades de apoyo y sus demandas a las universidades (Pastor y Peraita, 2012).

La investigación de las universidades tendrá tanto mayor valor social cuanto más active este círculo de inter-apoyo virtuoso. Para ello sus resultados deben medirse en cómo contribuyen al desarrollo económico y social, en sus pasos sucesivos: conocimiento creado; su transferencia para aplicaciones de innovación y desarrollo; competitividad del sistema productivo, y, finalmente, modelo de sociedad y bienestar propio (autónomo, elegido libremente). La Figura 1 ilustra esta cadena enganchada a la investigación, propia de las sociedades de economía innovadora, en cuyo colectivo se encuentra España, tanto en su conjunto, como parcelada en sus diferentes Comunidades Autónomas.

El gráfico que acompaña a la Figura 1 indica la relación entre resultado inmediato de la investigación, conocimiento generado, verdadera materia prima sobre el que apoyar el crecimiento de una sociedad, y que es válido para sus ejecutores, los investigadores, y lo que demanda la sociedad: crecimiento desde la innovación y la competitividad productiva. Como existe un ángulo máximo para optimizar el alcance del tiro parabólico, en cuyo modelo se basa cualitativamente la relación planteada, el desarrollo requiere de una inversión óptima en conocimiento con la que se obtienen valores máximos de los resultados posibles, siempre que se canalice adecuadamente la transferencia del conocimiento generado, siendo este último la altura en el modelo. Es importante acomodar la inversión adecuada para que el conocimiento creado sea aprovechado con máxima capacidad de transferencia, no sobrepasarla pues alcanzar mayores cotas de conocimiento no supondría mayor capacidad de transferencia, haciendo ineficaz la inversión.

Así, analizar la investigación como valor social de las universidades, entidades a considerar sin duda como bien público, exige valorar sus resultados de generación de conocimiento, la inversión realizada, y los resultados de innovación y competitividad alcanzados, como consecuencia de su transferibilidad, en el sistema relacional universidad-entorno considerado. También comparar las relaciones de causa-efecto establecidas entre sistemas semejantes dentro de sociedades pertenecientes al mismo modelo de economía y de anhelo de bienestar social. Se podría así comparar el valor social de la investigación de diferentes universidades o, por agrupación de estas, de sistemas universitarios completos. Aquí se hace el análisis desde la perspectiva del SUE, Sistema Universitario Español, en su relación con su efecto sobre la sociedad española en su conjunto. 


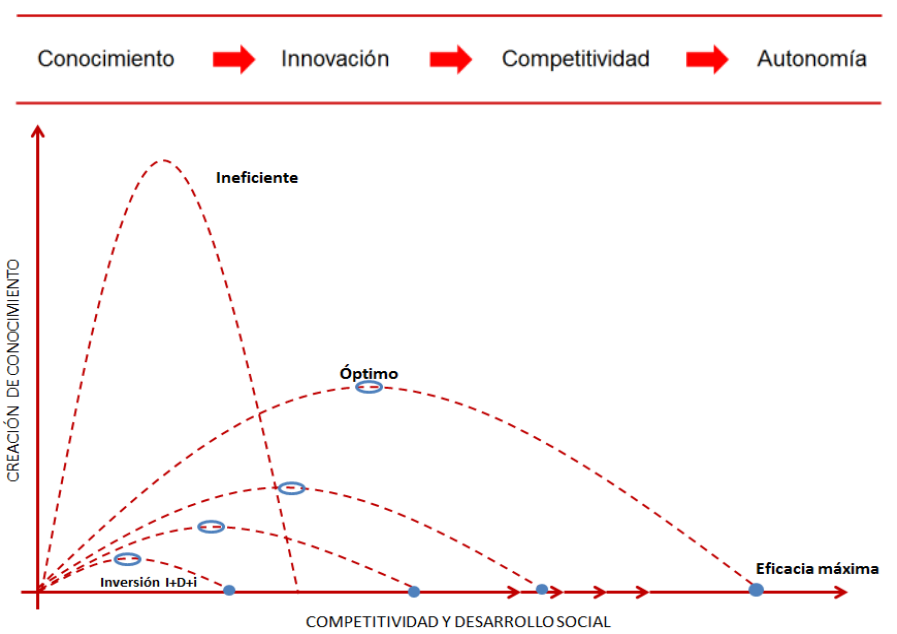

Figura 1. Flujos y modelo de gestión del conocimiento para el desarrollo social. Fuente: Elaboración propia

\section{Resultados de investigación del SUE en relación a su valor social}

El Sistema Universitario Español (SUE), en su conjunto, es el responsable de la mayoría (en torno al 70\%) de la producción científica española total, por lo que esta se usa en este análisis. España, y con ello el SUE, presenta un buen posicionamiento internacional en la cantidad de su producción científica (10 posición de España como país en documentos acumulados 1996-2015 lo que representa el $3.4 \%$ del total mundial), con una calidad que ha mejorado mucho, pero aún debe hacerlo más, ocupando la posición 21 en citas por documento, algo menos de 2/3 del sistema de más calidad, el suizo, y que en un indicador intermedio como es el índice $\mathrm{H}$ ocupa el puesto 12 a nivel mundial (SJR, 2016; Fundación Conocimienot y Desarrollo, 2015) (Figura 2).

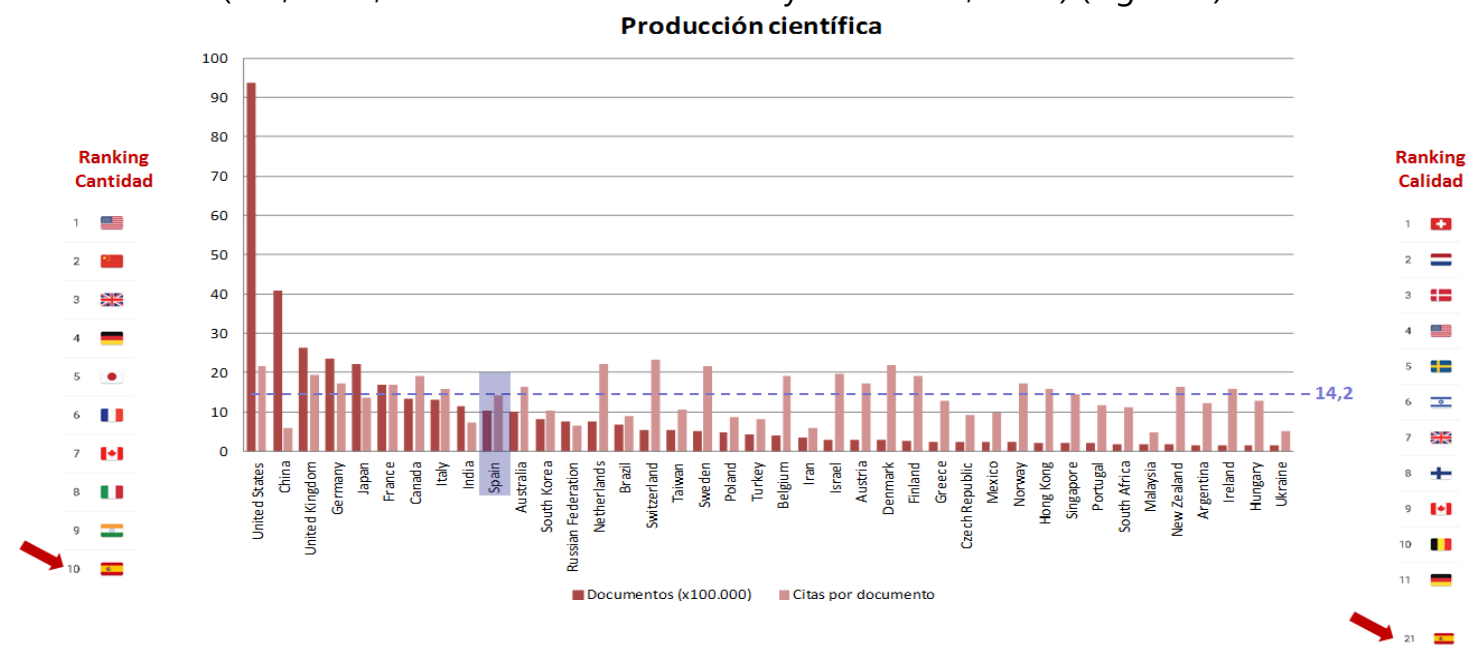

Figura 2. Producción científica por países en cantidad y calidad. Fuente: Scimago. Datos acumulativos 1996-2016

Al considerar la evolución temporal (Figura 3), tanto en cantidad como en calidad, se nota, tras unos máximos en 2014-2015, un ligero retroceso, rompiendo la espectacular tasa de crecimiento sostenida desde 2002 (Thomson Reuters Web of Science, 2016). 
Top Papers (\%)
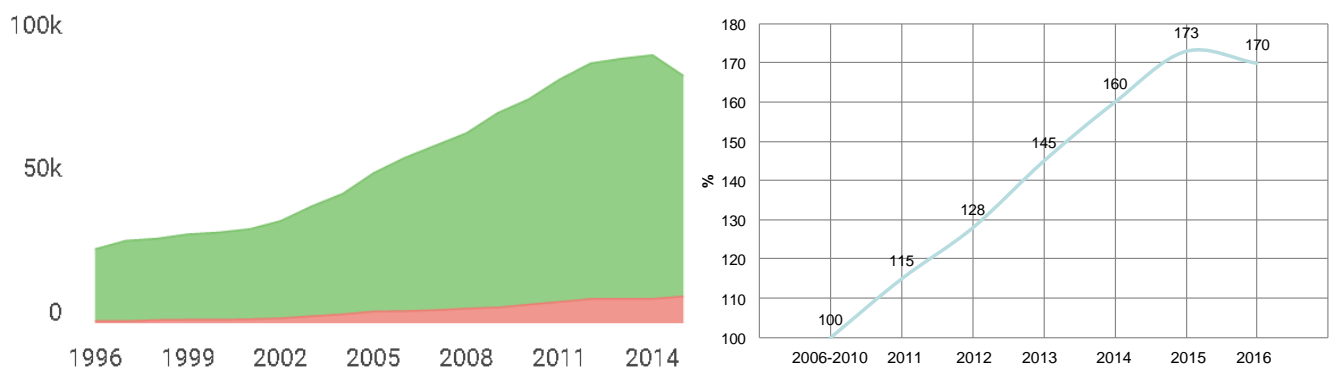

Figura 3. Evolución de la cantidad y calidad de la producción científica espanyola. Fuente: Scimago. Web of Science y elaboración propia

Para poder considerar estos resultados en el contexto de valor social, debe considerarse la eficiencia y la eficacia de los mismos y compararlos con los recursos aportados por la sociedad en su conjunto. Resulta, para ello, importante enmarcar el análisis en comparación con aquellos sistemas universitarios en modelos de sociedad semejante a la nuestra, con una economía basada en el conocimiento y con principios de priorización del bienestar social como compromiso de estado. La Figura 4, al comparar los países top en calidad y en cantidad en generación de conocimiento, nos permite justificar qué países europeos y de tamaño semejante al nuestro, como Alemania, Gran Bretaña o Francia, e incluso alguno más pequeño como Holanda, junto con países con población semejante como Canadá o Australia, deben ser referentes comparativos, entre otros.

\section{¿Con quién compararnos?}

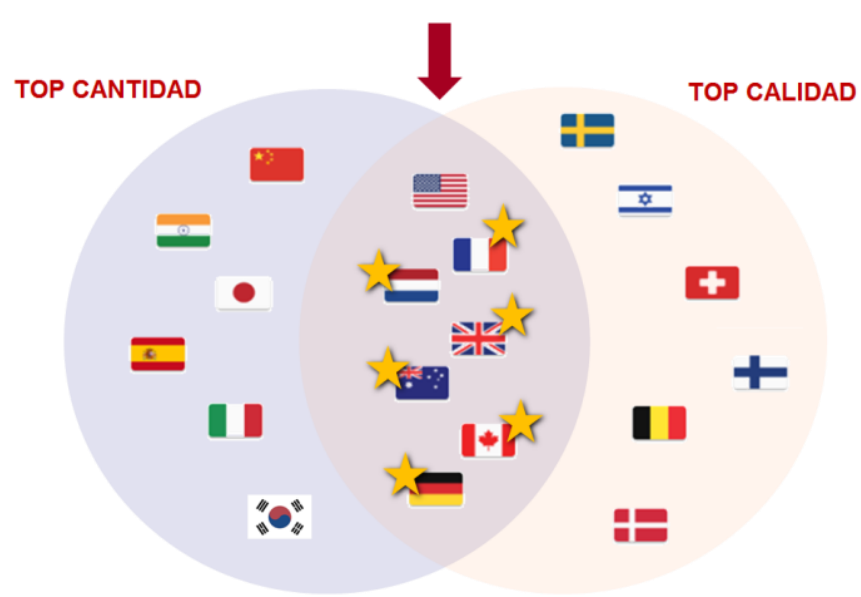

Figura 4. Países top en cantidad y calidad de producción científica.

Fuente: Scimago. Datos acumulativos 1996-2015. Elaboración propia.

Estos resultados de producción científica en cantidad y calidad implican una gran eficiencia de la labor investigadora, de generación de nuevo conocimiento, de las universidades al compararla con la inversión total del país en I+D+i, 1,23\% PIB y en descenso (Figura 5) (CRUE Universidades Españolas, 2015). Esta inversión queda muy por debajo de los valores umbrales que garantizan posicionarse en la élite de competitividad de las economías del conocimiento (Figura 6) (Gutiérrez-Solana y Valle, 2013). Por tanto, ya tenemos un primer hecho que justifica que la investigación española no logra las cotas de eficacia que interesan a la sociedad, ya que la competitividad no alcanza el nivel deseado: la inversión que la propia sociedad en su conjunto dedica a la investigación no es adecuada. 

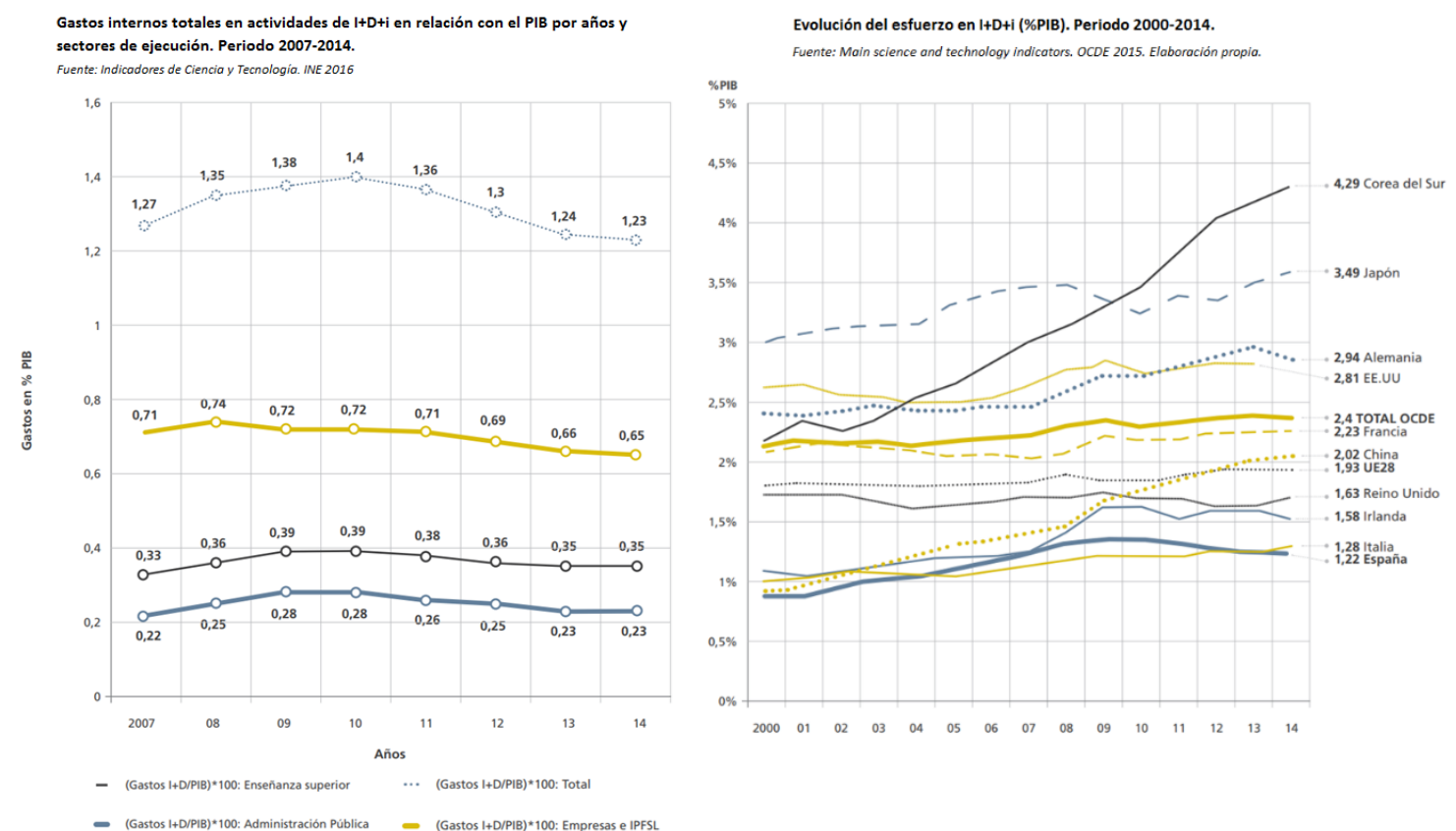

Figura 5. Evolución de la inversión española en $I+D+i$, por sectores y comparada con otros países. Fuente: Informe La Universidad Española en cifras 2014-2015.

Se deben analizar, por tanto, los recursos financieros de la investigación española, y del SUE en particular. La propia Figura 5 indica cómo el esfuerzo de inversión en I+D+i española, en descenso, está, en referencia al PIB, muy por debajo (un 61\%) de la media de la UE de los 28 y (un 50\%) de la media de países OCDE.

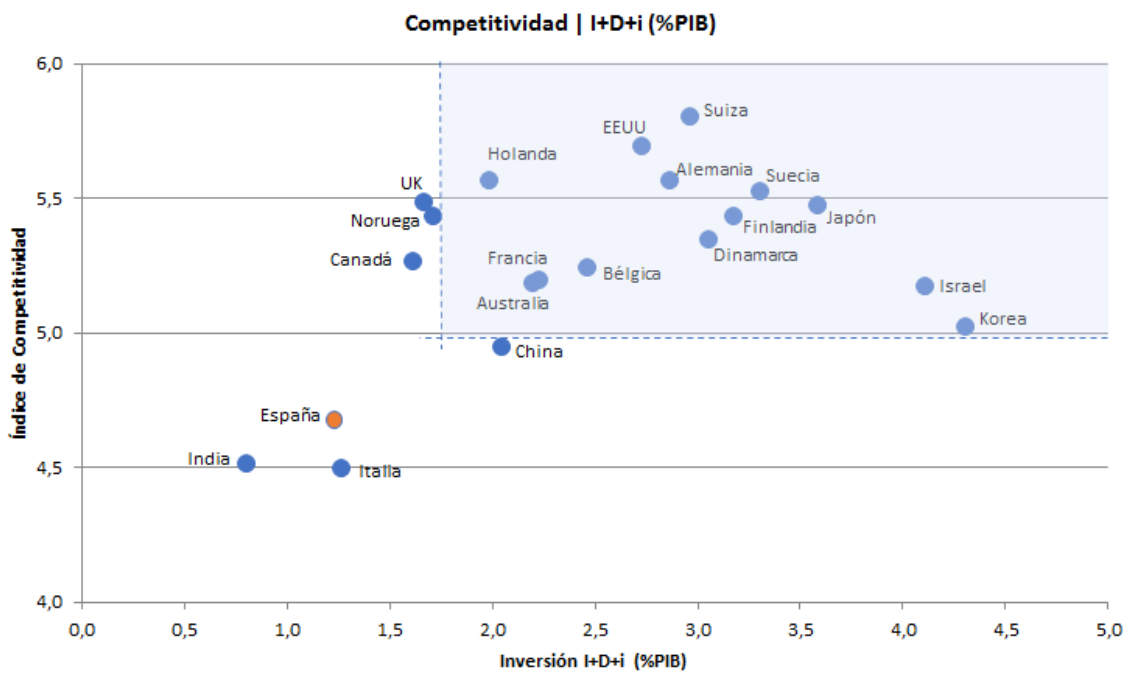

Figura 6. Relación Competitividad - Inversión en I+D+i.

Fuente: Elaboración propia.

Comparando con apoyo en la Tabla1, para los países seleccionados en la Figura 4 como referenciales, los resultados de generación de conocimiento en cantidad, medidos por el número 
de publicaciones por millón de habitantes para evitar el efecto poblacional, con respecto a su inversión en $\mathrm{I}+\mathrm{D}+\mathrm{i}$ referida al $\mathrm{PIB}$, nos encontramos con la gran eficiencia de la investigación española en producción científica, solo superada nítidamente por países como Noruega, Holanda, Reino Unido, Canadá y Suiza, como se ve en la Figura 7.

\begin{tabular}{|c|c|c|c|c|c|c|c|c|c|}
\hline \multirow{2}{*}{ País } & \multirow{2}{*}{ Referencia } & \multirow{2}{*}{ Publicaciones } & \multirow{2}{*}{$\begin{array}{c}\text { Publicaciones/ } \\
\text { M. hab. }\end{array}$} & \multirow{2}{*}{ Citas/doc } & \multirow{2}{*}{$\begin{array}{c}\text { Inversión I+D+i } \\
\text { Tot. (\%PIB) }\end{array}$} & \multicolumn{2}{|c|}{ Innovación (2017) } & \multicolumn{2}{|c|}{ Competitividad (2017) } \\
\hline & & & & & & Ranking & Índice & Ranking & Índice \\
\hline Estados Unidos & Calidad+Cantidad & 10.194 .000 & 31.560 & 23,58 & 2,72 & 4 & 61,40 & 3 & 5,70 \\
\hline Reino Unido & Calidad+Cantidad & 2.899 .000 & 43.991 & 21,04 & 1,66 & 5 & 60,90 & 7 & 5,49 \\
\hline Alemania & Calidad+Cantidad & 2.570 .000 & 31.114 & 19,07 & 2,86 & 9 & 58,40 & 5 & 5,57 \\
\hline Francia & Calidad+Cantidad & 1.827 .000 & 28.238 & 18,56 & 2,22 & 15 & 54,20 & 21 & 5,20 \\
\hline Canadá & Calidad+Cantidad & 1.469 .000 & 41.971 & 21,14 & 1,61 & 18 & 53,70 & 15 & 5,27 \\
\hline Australia & Calidad+Cantidad & 1.111 .000 & 44.980 & 18,33 & 2,19 & 23 & 51,80 & 22 & 5,19 \\
\hline Holanda & Calidad+Cantidad & 816.000 & 47.719 & 24,67 & 1,98 & 3 & 63,40 & 4 & 5,57 \\
\hline Suiza & Calidad & 596.000 & 70.952 & 25,64 & 2,96 & 1 & 67,70 & 1 & 5,81 \\
\hline Suecia & Calidad & 552.000 & 55.200 & 23,59 & 3,30 & 2 & 63,80 & 6 & 5,53 \\
\hline Bélgica & Calidad & 447.000 & 39.558 & 21,28 & 2,46 & 27 & 49,90 & 17 & 5,25 \\
\hline Dinamarca & Calidad & 323.000 & 56.667 & 24,28 & 3,05 & 6 & 58,70 & 12 & 5,35 \\
\hline Israel & Calidad & 321.000 & 40.125 & 21,70 & 4,10 & 17 & 53,90 & 24 & 5,18 \\
\hline Finlandia & Calidad & 282.000 & 51.273 & 21,17 & 3,17 & 8 & 58,50 & 10 & 5,44 \\
\hline Noruega & Calidad & 255.000 & 49.038 & 19,25 & 1,71 & 19 & 53,10 & 11 & 5,44 \\
\hline China & Cantidad & 4.595 .000 & 3.330 & 7,10 & 2,04 & 22 & 52,50 & 28 & 4,95 \\
\hline Japón & Cantidad & 2.368 .000 & 18.646 & 14,98 & 3,58 & 14 & 54,70 & 8 & 5,48 \\
\hline Italia & Cantidad & 1.449 .000 & 23.871 & 17,50 & 1,26 & 29 & 47,00 & 44 & 4,50 \\
\hline India & Cantidad & 1.303 .000 & 983 & 8,32 & 0,80 & 60 & 35,50 & 39 & 4,52 \\
\hline España & Cantidad & 1.148 .000 & 24.688 & 15,89 & 1,23 & 28 & 48,80 & 32 & 4,68 \\
\hline Korea & Cantidad & 915.000 & 17.941 & 11,75 & 4,30 & 11 & 57,70 & 26 & 5,03 \\
\hline
\end{tabular}

Tabla 1. Indicadores de producción científica, inversión en I+D+i, innovación y competitividad. Fuente: Elaboración propia.

Al comparar la calidad de los resultados científicos, citas por artículo (Figura 8), se observa de nuevo una gran eficiencia para España superada esta vez solo y apenas por Italia y Canadá. A su vez también se observa que sin incrementar su esfuerzo inversor al menos en un $40 \%$, hasta alcanzar valores próximos a la media de la UE, no es posible llegar a las deseables cotas de un $25 \%$ más de citas con las que se estaría en el grupo top de calidad, que está además contenido en el de los países más competitivos.

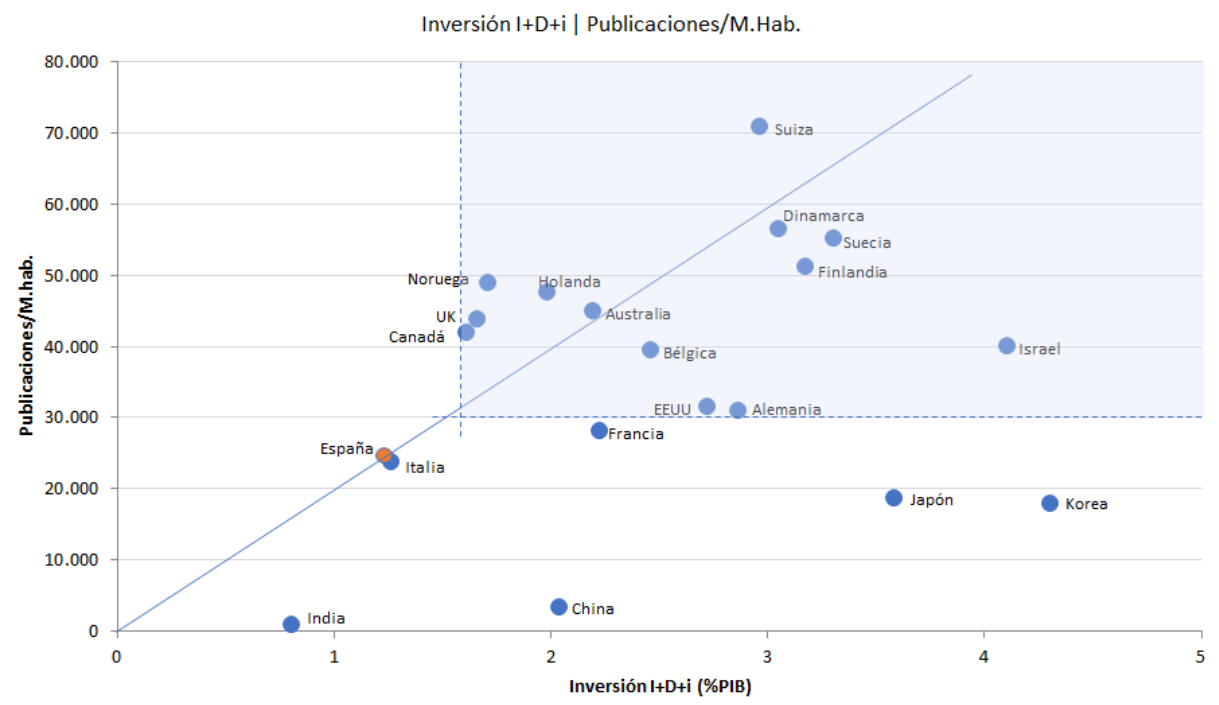

Figura 7. Relación Cantidad de producción científica - Inversión I+D+i. Fuente: Elaboración propia.

Observando las Figuras 7 y 8 se ve ya la similitud entre las relaciones de la calidad y de la cantidad de los resultados científicos, eliminado el efecto del tamaño poblacional, con el esfuerzo en inversión, de forma que hay un crecimiento de los resultados científicos proporcional a la 
inversión hasta valores de esta próximos al $2 \%$ del PIB, situación umbral de inicio de una segunda zona en la que los valores de calidad tienden a estabilizarse en el rango de 20 a 25 citas/documento y por encima de 40.000 publicaciones por millón de habitantes en 20 años.

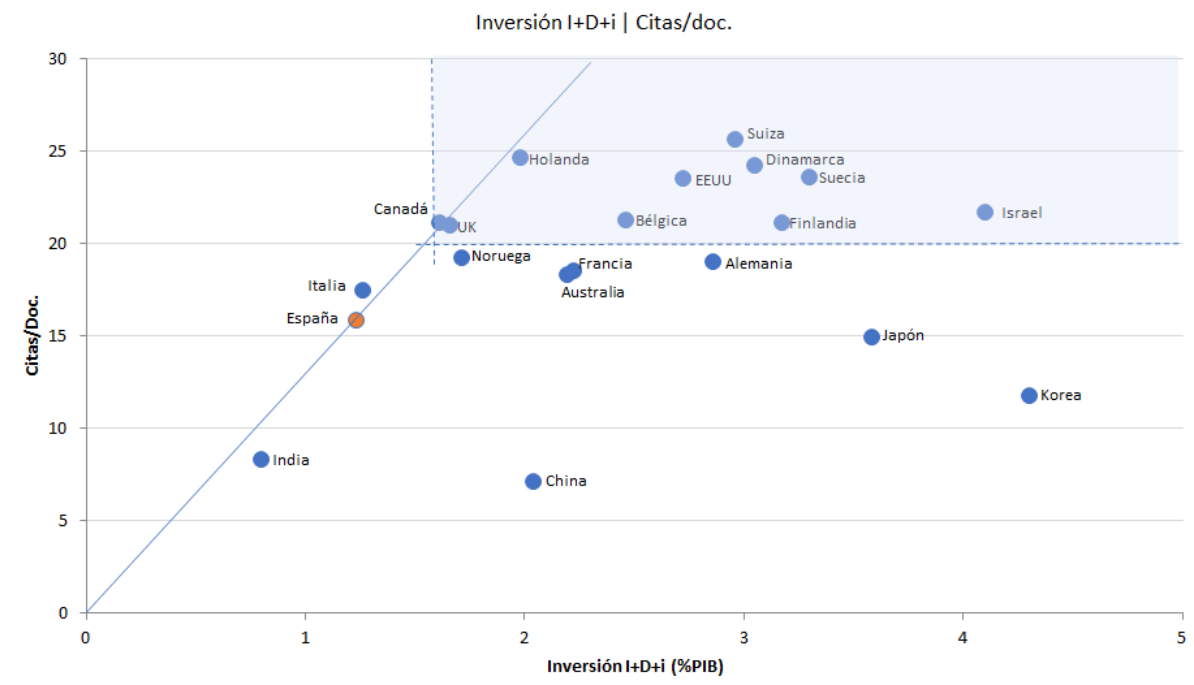

Figura 8. Relación Calidad de producción científica - Inversión en I+D+i.

Fuente: Elaboración propia.

Las excepciones, con mucha menor eficiencia, corresponden a los países asiáticos por diversas razones, poblacionales, culturales e idiomáticas. Así, la Figura 9 muestra cómo hay una gran correlación entre calidad y cantidad científica y cómo entrar en la zona de máximo rendimiento requiere en general valores de inversión al menos del $2 \%$ del PIB.

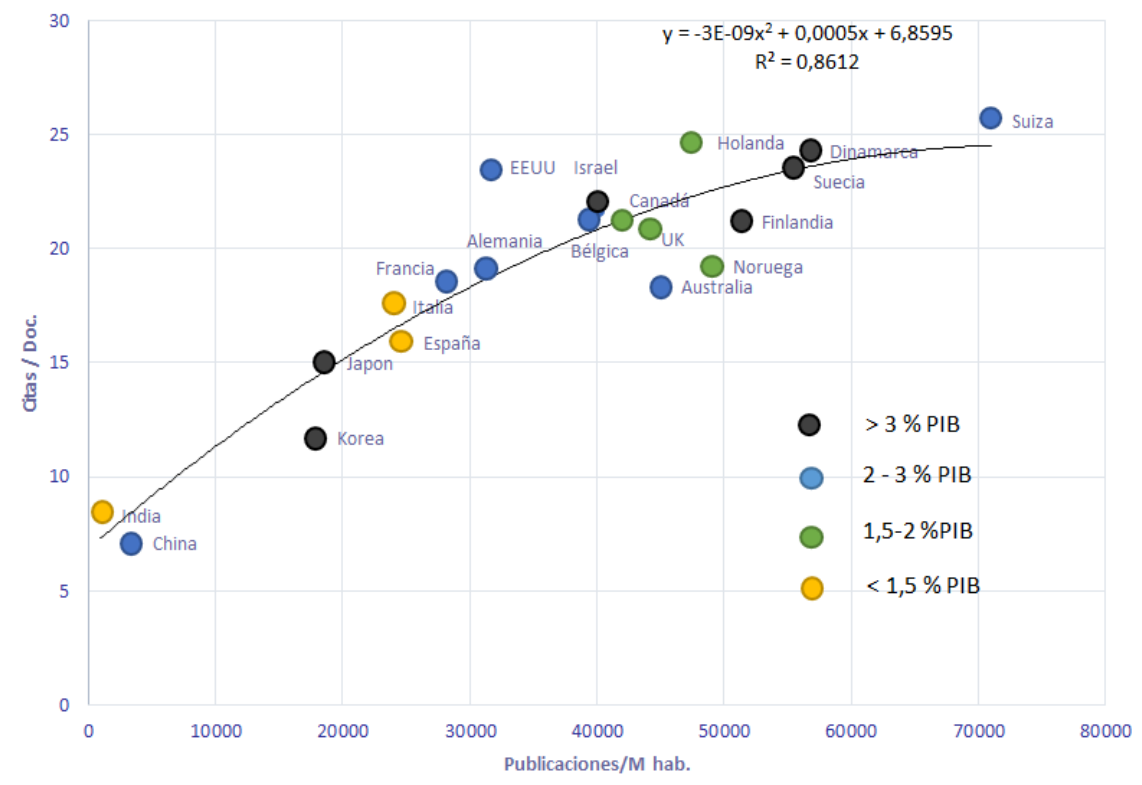

Figura 9. Relación entre cantidad y calidad de la producción científica.

Fuente: Elaboración propia

Cuando esta situación de generación de conocimiento en cantidad y calidad se compara con la inversión propia de las universidades en $I+D+i$, teniendo en cuenta que porcentualmente sobre el total esta es en España mayor que en otros países (Figura 10), las correlaciones empeoran para 
España, fundamentalmente con respecto a Francia, 30\%, y Alemania, 45\%, aunque sigue manteniéndose más eficiente, $12 \%$ y $20 \%$, que ambas (Fundación COTEC, 2016).

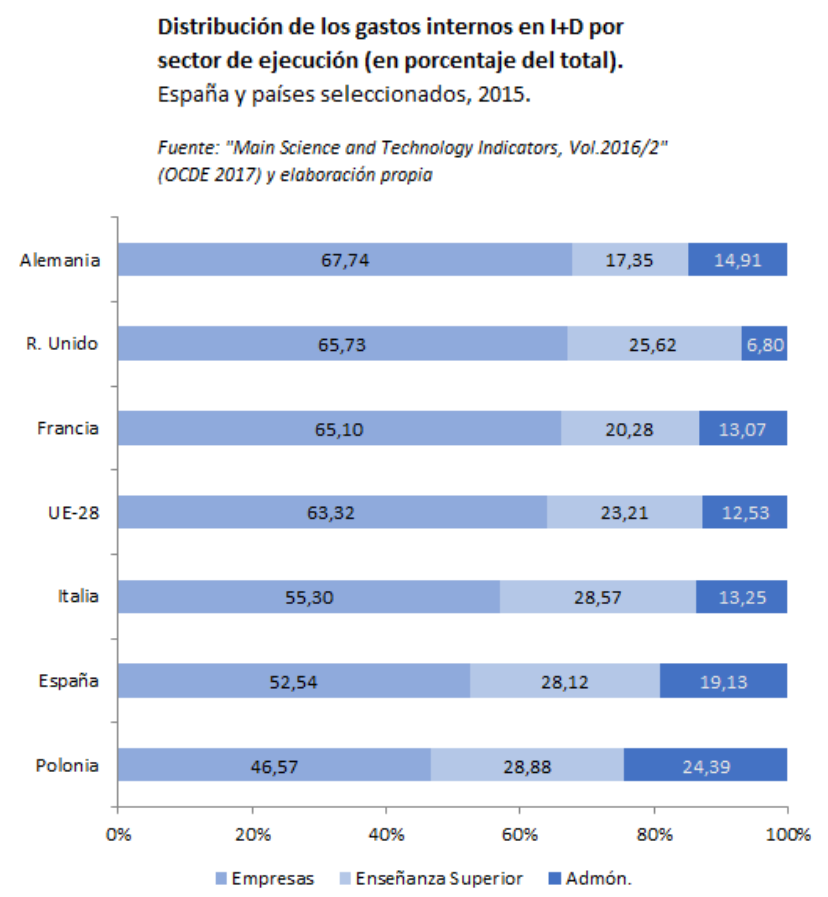

Figura 10. Distribución de la inversión en I+D+i comparada entre países.

Fuente: COTEC Informe 2017 y elaboración propia.

Esto evidencia que no sólo es importante invertir adecuadamente en investigación e innovación, sino hacerlo equilibradamente entre los diferentes agentes responsables de ello, las empresas, las administraciones públicas y las universidades, como modo de garantizar que la investigación forme parte del inicio de la cadena del conocimiento establecida para propiciar crecimiento social y se optimice así su eficacia. En este sentido, la distribución de la inversión española no está equilibrada en la manera en la que lo hacen los países más eficaces. Para estar al nivel de la media europea, las empresas españolas, que llevan reduciendo su inversión de año en año desde el inicio de la crisis, Figura 5, deben incrementar en un $78 \%$ su inversión, de $0,65 \%$ al entorno de $1,15 \%$ del PIB. Mientras administraciones públicas y universidades han de incrementar su inversión en menor manera, en torno a un $20 \%$, hasta alcanzar un valor mínimo, suma de ambas, del orden del $0,70 \%$ del PIB.

Con sus valores absolutos y su distribución, la inversión en I+D+i actual no puede augurar unos resultados en la transferencia que sean propios de los objetivos de una sociedad que basa su crecimiento en el conocimiento y en su aplicación innovadora. En efecto, la Figura 11 (CRUE Universidades Españolas, 2015) muestra, con el más clásico de los indicadores de transferencia, el número de patentes referido al PIB, un mal posicionamiento de España como país, con valores relativos inferiores en 6 veces a Reino Unido, u 8 veces con respecto a Francia (4 veces menos eficiente que cualquiera de ellas), o casi 14 veces inferior a Alemania (casi 6 veces menos eficiente). 


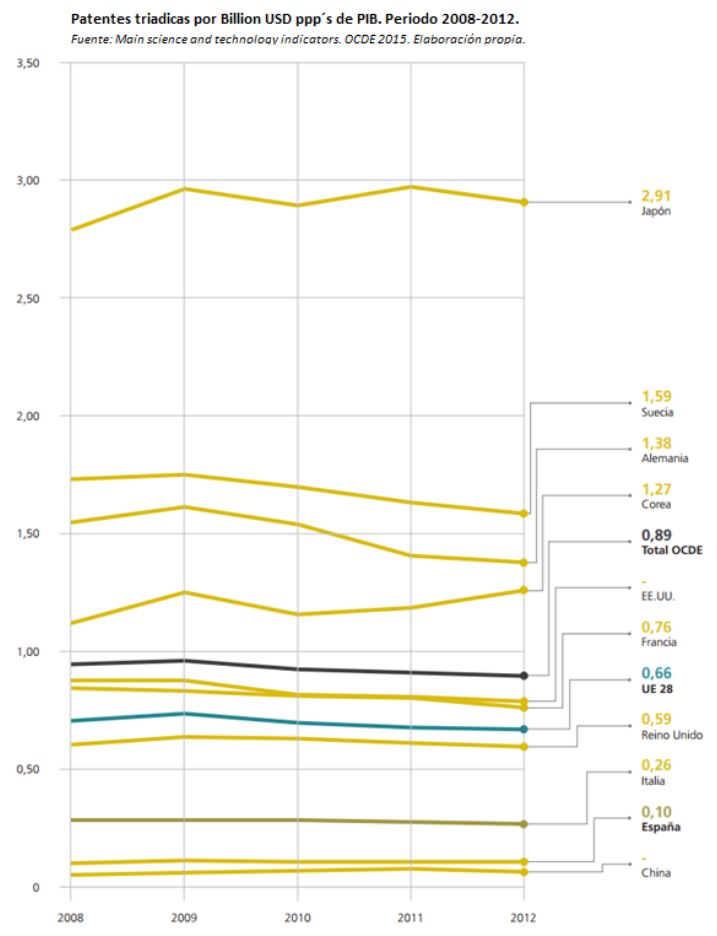

Figura 11. Evolución de patentes relativas a la inversión en $I+D+i$ de distintos paises. Fuente: Informe La Universidad Española en cifras 2014-2015.

Otros indicadores nos pueden mostrar de nuevo la falta de eficacia de nuestro modelo, que sólo mantiene la eficiencia de la inversión en el primero de los eslabones de la cadena del conocimiento para el desarrollo, su generación, pero perdiéndola en el siguiente de la transferencia. Así, la Figura 12 (CRUE Universidades Españolas, 2015) muestra la debilidad española en incluir productos de alta tecnología, basados en la aplicación innovadora del conocimiento, en sus exportaciones, con valores relativos 3 veces inferiores a Alemania y Reino Unido o 4 veces a Holanda o Francia.

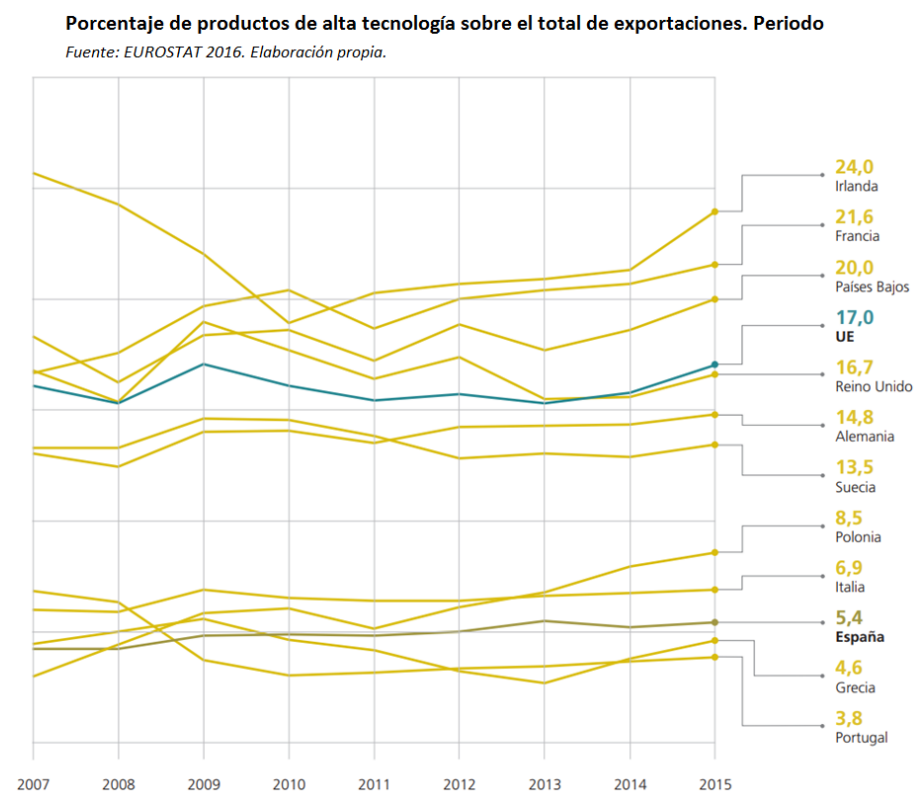

Figura 12. Evolución de la presencia de alta tecnología en la capacidad productiva de diferentes países. Fuente: Informe La Universidad Española en cifras 2014-2015. 
La transferencia del conocimiento para la innovación requiere de la voluntad de sus dos extremos, los generadores de conocimiento, entre los que las universidades son mayoritarias, y los receptores-transformadores-aplicadores, fundamentalmente las empresas. La investigación de las universidades tendrá tanto mayor valor social cuanto más active este círculo de inter-apoyo virtuoso. La inversión realizada para activar este círculo no es lo suficientemente potente para sobrepasar los umbrales que marcan la colaboración eficaz. Algunos indicadores, como la actividad en patentes (Figura 13), evidencian que las universidades se han activado en la transferencia, más que duplicando sus patentes en 5 años. A pesar de ello no logran mejorar resultados en recursos generados por su transferencia al mercado de esta actividad, que se mantienen prácticamente constantes (CRUE Universidades Españolas, 2015) por falta de mejora en la transferibilidad del conocimiento que guarda.

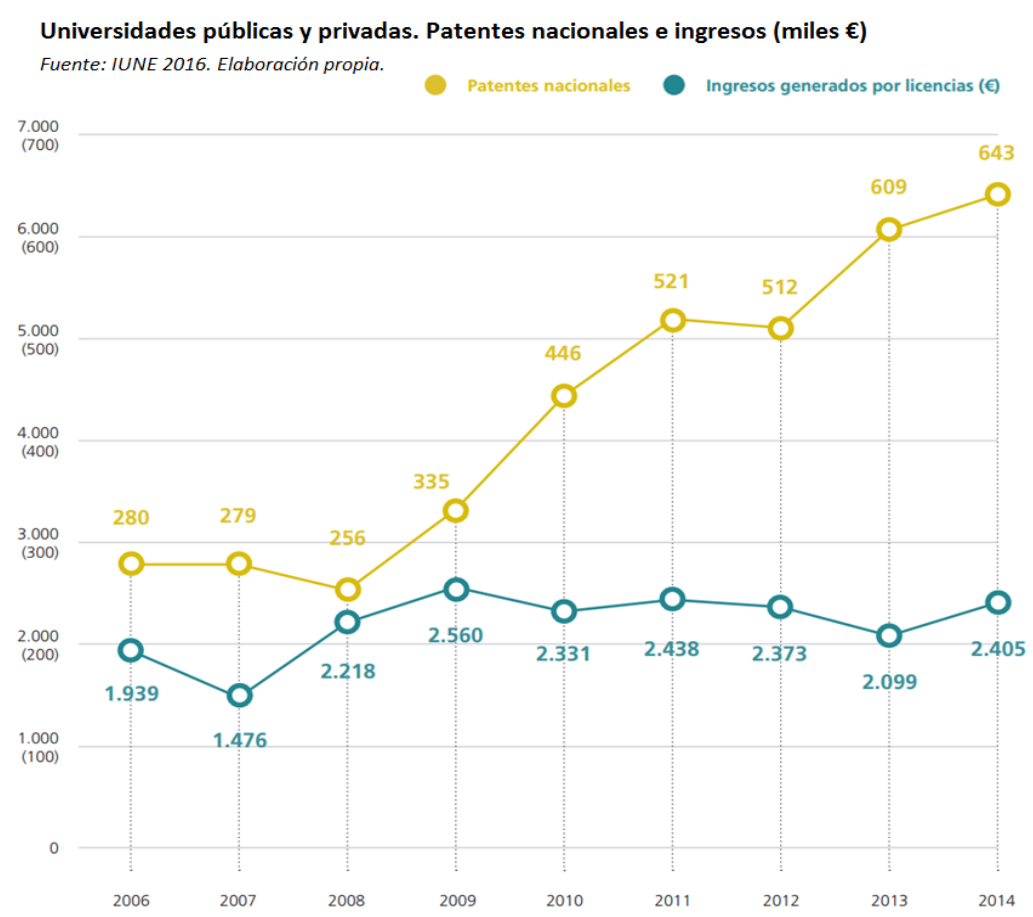

Figura 13. Evolución de patentes de las universidades españolas y sus ingresos Fuente: Informe La Universidad Española en cifras 2014-2015.

Por tanto, no solo la inversión que la propia sociedad en su conjunto dedica a la investigación no es la adecuada, sino que además la participación en ella de los agentes empresariales, que necesita casi duplicarse, denota su falta de cultura innovadora lo que rompe la cadena del conocimiento aplicado al desarrollo e impide la capacidad de colaboración mutua de círculo virtuoso entre universidad y empresa.

Y esto que vale para España en su conjunto, tiene su réplica en prácticamente cada uno de los sistemas universitarios autonómicos, pues las mismas debilidades de cultura innovadora e inversión en generación y transferencia de conocimiento afloran en cada une una de nuestras comunidades, Figura 14 (Fundación COTEC, 2016). Las excepciones se encuentran en el País Vasco, superior en su inversión a la media de la UE, Madrid, Navarra, y Cataluña, estas entre 1,7\% y 1,5\% de su PIB de inversión en I+D+i. Además, son dos de estas cuatro comunidades, País Vasco y Navarra, las que presentan una participación empresarial en su inversión por encima del $60 \%$, estando las otras dos próximas a ello. Con todo, la tendencia al decrecimiento en la inversión en los últimos años también ha sido seguido por estas comunidades de modelo más inversor en I+D+i. 


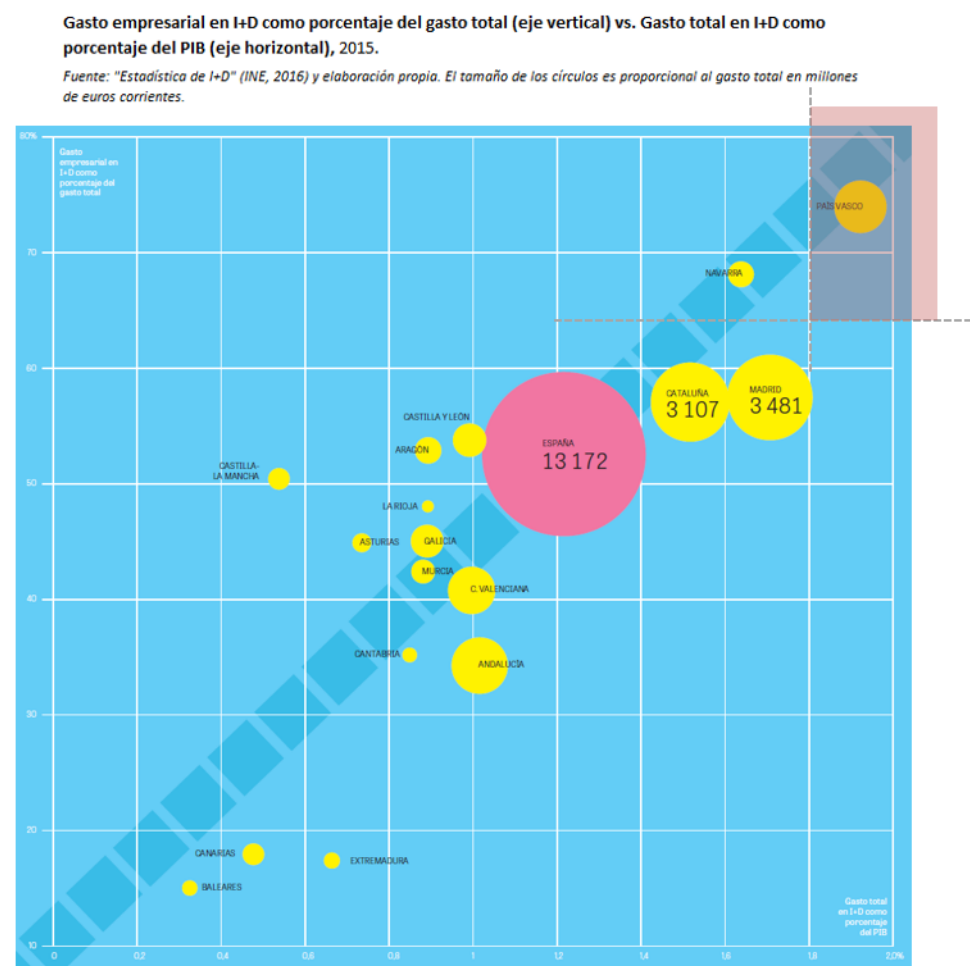

Figura 14. Inversión en I+D+i total y empresarial en las CCAA españolas. Fuente: COTEC Informe 2017. Elaboración propia

Esta falta de cultura innovadora, su consecuente influencia en una pobre cultura inversora en conocimiento y el déficit que ello conlleva de pérdida de la tendencia adecuada, supone para las universidades una falta de clima propicio en el que desarrollar su investigación y, particularmente, transferir sus resultados, no accediendo a estimular el círculo virtuoso de colaboración establecido. De ahí que las universidades españolas con producción investigadora tienen una capacidad inversora en $\mathrm{I}+\mathrm{D}+\mathrm{i}$ sustancialmente menor que las de otros países con estructuras socio-económicas semejantes (CRUE Universidades Españolas, 2015).
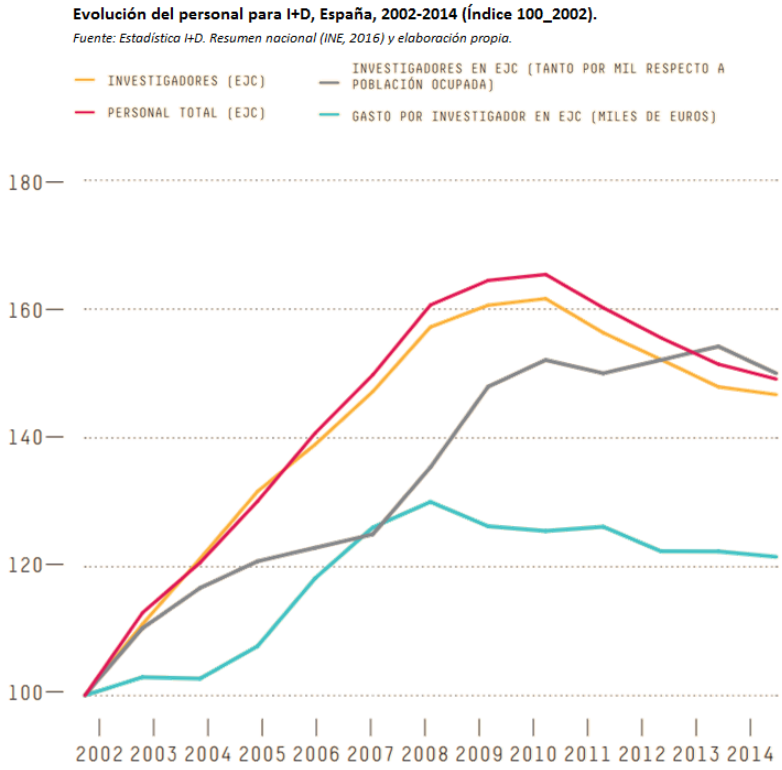

Figura 15. Evalución de RRHH en investigación y su financiación. Fuente: COTEC Informe 2016. 
La baja capacidad inversora y el cambio de su evolución (de creciente a decreciente) traen como consecuencia la pérdida de un $10 \%$ de los investigadores del SUE, incluyendo más de un $4 \%$ de profesorado investigador (CRUE Universidades Españolas, 2015), y, además, casi un 7\% en la inversión por investigador en los últimos cuatro años (Figura 15 y Figura 16), lo que se convierte en el más claro indicador de ineficiencia e ineficacia de la función universitaria puesto que se pierde la inversión previamente realizada en recursos humanos formados. Pérdida que conlleva, asimismo, la caída de productividad científica en España y, además, que de los resultados de la actividad de algunos de los investigadores, consolidados o en formación, españoles que han tenido que abandonar el SUE se beneficien otros sistemas, que sí han sabido invertir en ellos (Fundación COTEC, 2016; Alianza 4 Universidades, 2016). El cambio de tendencia inversora en los últimos 8 años ha hecho que España perdiera el camino ganado en recortar distancias en densidad de recursos humanos para la investigación con países como Francia o Alemania, y con respecto a la media europea, que en 2009 prácticamente se había alcanzado (Figura 17).

\section{El Confidencial}

Sigue la fuga de cerebros: España pierde un $10 \%$ de sus investigadores en cuatro años

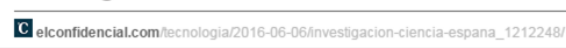

Pérdida de:

$-10,12 \%$ de investigadores

$-6,7 \%$ financiación/investigador

Figura 16. Evaluación de RRHH en investigación y su financiación. Fuente: IUNE 2016 y elaboración propia.

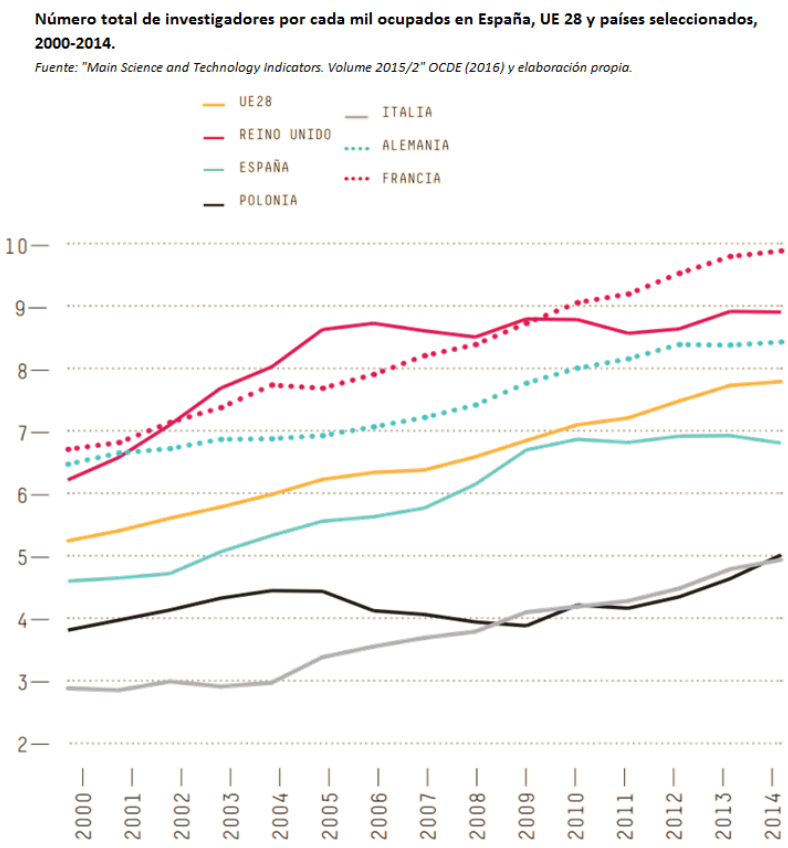

Figura 17. Evolución de investigadores comparada entre países. Fuente: COTEC Informe 2016.

En este contexto, España, siendo la quinta potencia económica-social europea, se sitúa como duodécimo país en un indicador sobre excelencia de la investigación y la transferencia de sus resultados, en cuya aportación las universidades son el principal actor, por debajo del valor medio 
europeo (Figura 18) (European Commission, 2014). Este indicador aparece liderado por Holanda, que conjuga máxima eficiencia con alta eficacia en su modelo de generación y transferencia de conocimiento con una inversión en el umbral requerido del entorno del $2 \%$ del PIB. En atención a todo lo analizado previamente, no hay sorpresas entre los países que superan en este indicador la media europea y tampoco entre los que no lo hacen, como España o Italia.

\begin{tabular}{|l|c|}
\hline & $\begin{array}{c}\text { Composite indicator of research } \\
\text { excelence } \\
2010\end{array}$ \\
\hline EU27 average & 47,9 \\
\hline EU27 70\% threshold & 33,5 \\
\hline Member States below 70\% of the EU27 value \\
\hline Latvia & 11,5 \\
\hline Croatia & 12,2 \\
\hline Lithuania & 13,9 \\
\hline Malta & 17,5 \\
\hline Slovakia & 17,7 \\
\hline Romania & 17,8 \\
\hline Luxembourg & 19,8 \\
\hline Poland & 20,5 \\
\hline Bulgaria & 24,7 \\
\hline Estonia & 25,9 \\
\hline Portugal & 26,5 \\
\hline Slovenia & 27,5 \\
\hline Cyprus & 27,8 \\
\hline Crech Republic & 29,9 \\
\hline Hungary & 31,9 \\
\hline
\end{tabular}

\begin{tabular}{|l|c|}
\hline \multicolumn{2}{|l|}{ Member States above 70\% of the EU27 value } \\
\hline Greece & 35,3 \\
\hline Spain & 36,6 \\
\hline Ireland & 38,1 \\
\hline Italy & 43,1 \\
\hline France & 48,2 \\
\hline Austria & 50,5 \\
\hline United Kingdom & 56,1 \\
\hline Belgium & 59,9 \\
\hline Germany & 62,8 \\
\hline Finland & 62,9 \\
\hline Sweden & 77,2 \\
\hline Denmark & 77,7 \\
\hline Netherlands & 78,9 \\
\hline
\end{tabular}

Figura 18. Índice de excelencia investigadora Fuente: European Commission (2014)

Es evidente que queda justificado que la sociedad española, en su conjunto, y sus agentes, empresas, administraciones, universidades, no hace lo suficiente para tener la capacidad investigadora e innovadora que el país necesita para ser competitivo. Porque tener bien implementada la capacidad innovadora requiere tener plenamente activados los mecanismos de la transferencia del conocimiento. Como se aprecia en la Figura 19, la innovación se convierte en el flujo potenciador de las empresas para su competitividad y una de las vías para acceder a ella es a través de la transferencia del conocimiento para procesos innovadores por parte de las universidades.

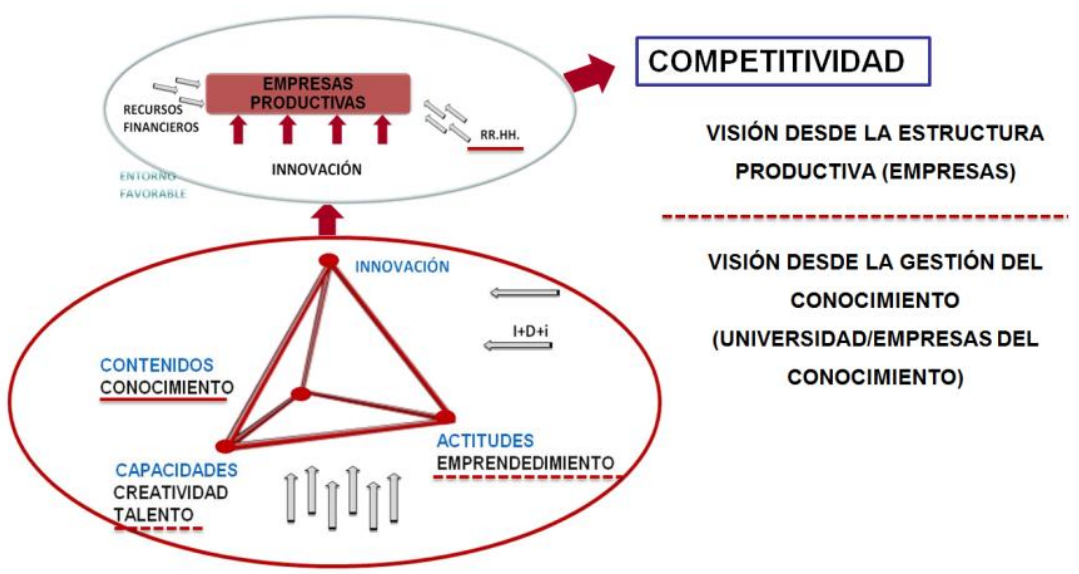

Figura 19. Esquema de las vinculaciones para la innovación y la competitividad. Fuente: Elaboración propia. 
Medida la capacidad innovadora a través de un índice global (Cornell INSEAD WIPO, 2017), España, como consecuencia de su modelo de I+D+i y su inversión en ello, ocupa el puesto 28 a nivel mundial, como se aprecia en la Tabla 1. La gráfica de la Figura 20 correlaciona la calidad científica de los países analizados con este indicador de innovación, si bien debe considerarse la dependencia del mismo en otros muchos factores determinantes del valor de su índice global. De igual manera, según lo que se aprecia en la Figura 9, se podría utilizar la producción científica relativa a la población, para ver la coincidencia entre países innovadores y países con calidad y alta producción científica.

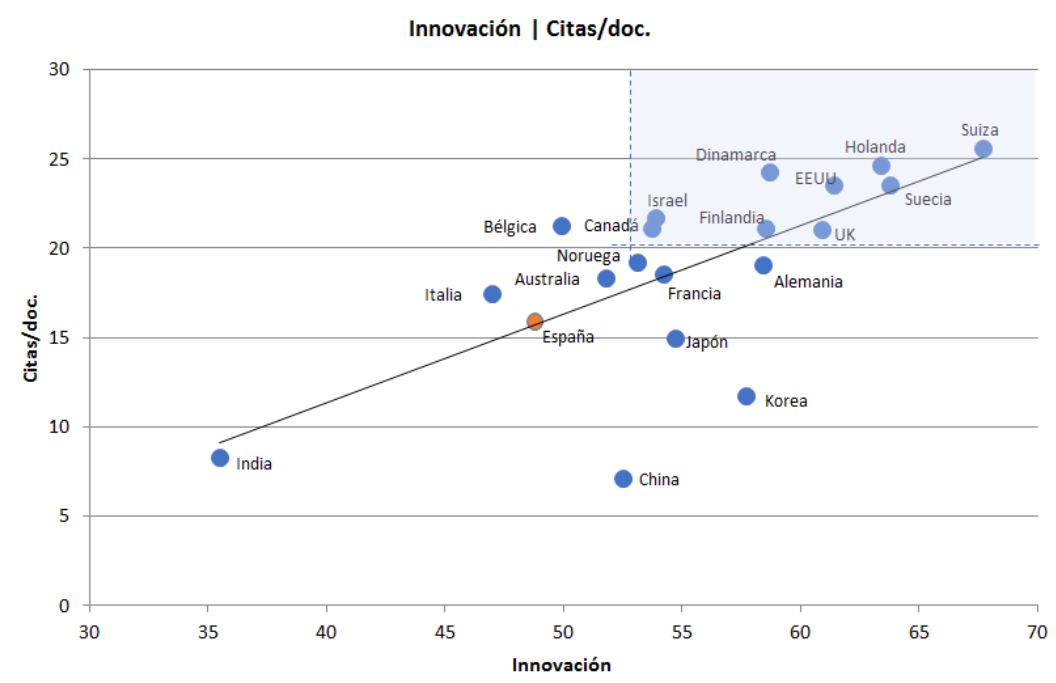

Figura 20. Relación Calidad científica - Innovación.

Fuente: Elaboración propia

Es esta baja capacidad innovadora causa principal que nos aleja de la élite de los países altamente competitivos, dentro de las economías avanzadas, como se aprecia en la Figura 21. Para alcanzar cotas de capacidad de innovación superiores, en las que se encuentran los países líderes, se necesita, como se aprecia en la Figura 22, superar umbrales de inversión en $\mathrm{I}+\mathrm{D}+\mathrm{i}$, en el entorno del $2 \%$ del PIB. (Figura 22).

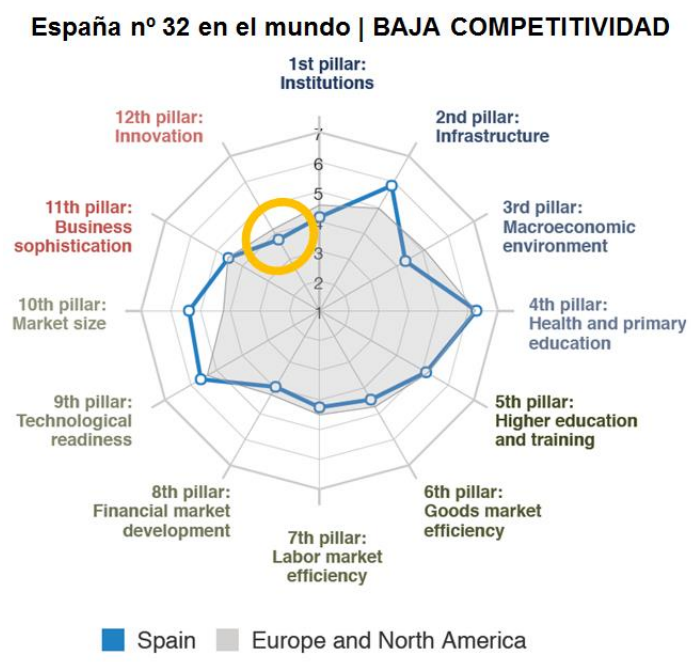

Figura 21. Factores para la competitividad en España. Fuente: Global Competitiveness Report 2016-17. 


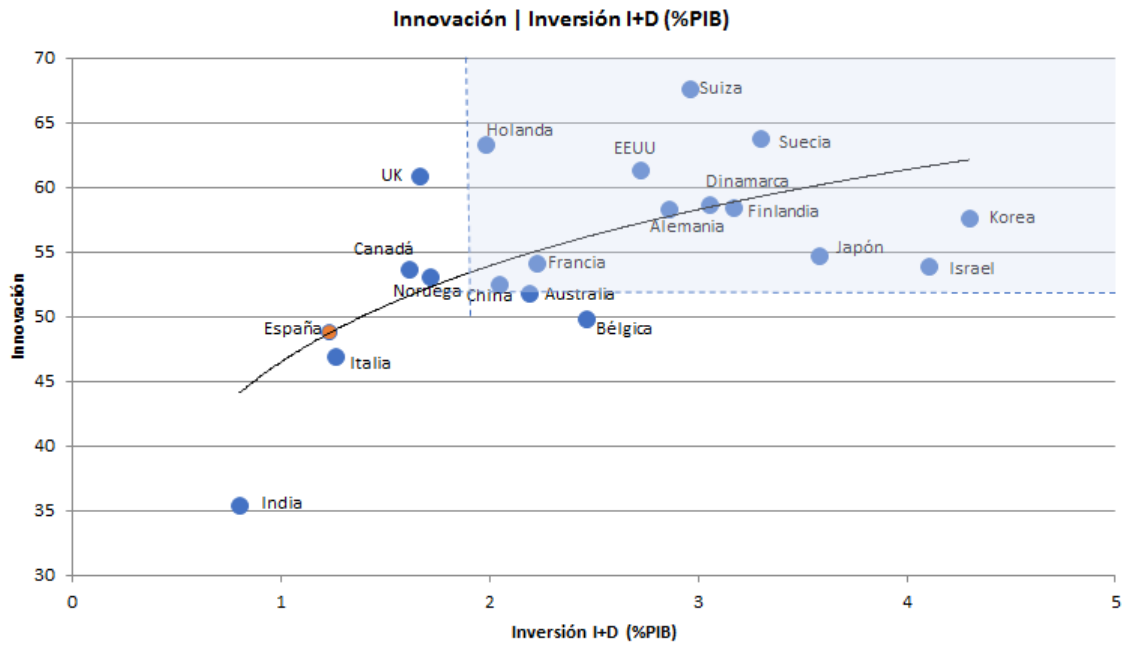

Figura 22. Relación Innovación - Inversión I+D+i. Fuente: Elaboración propia.

Volviendo al símil presentado en la Figura 1, la Figura 23 muestra la realidad del posicionamiento español frente al de otros países más competitivos y por tanto eficaces en la gestión del conocimiento. Como sociedad invierte mucho menos de lo que debe en $I+D+i(A)$, lo que otros países sí hacen (B); aun siendo eficiente (C) en generar conocimiento a partir de la inversión realizada, no es igualmente eficaz (D) al no tener afianzado un modelo de transferencia que promueva innovación y competitividad (E); a pesar de ello, su tendencia es a rebajar su inversión $(F)$, al contrario de lo que to hacen los países más sus competitivos competidores (G). Esta situación, que no difiere mucho de la que era hace seis u ocho años, ha empeorado en términos comparativos a otros países y en términos absolutos en los indicadores de recursos, inversión y personas implicadas, por lo que, si no se corrige, su tendencia será a agravarse.

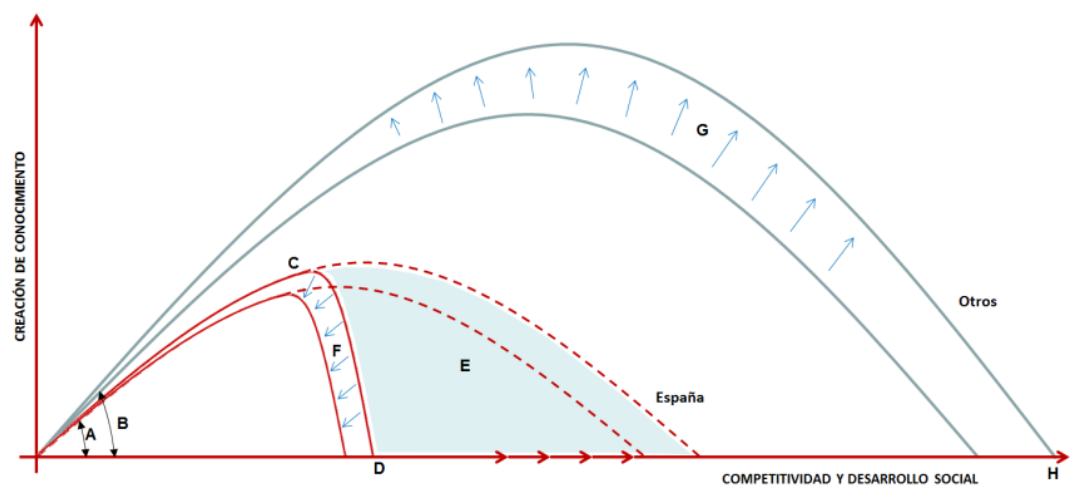

Figura 23. Características de la gestión del conocimiento para el desarrollo social: eficiencia/eficacia. Fuente: Elaboración propia.

La situación y la falta de adecuada tendencia en su mejora hace ver que la sociedad no valora adecuadamente el valor de la investigación y la innovación por lo que las universidades, como una de sus responsabilidades claves, tienen una labor inmensa de concienciación, de compromiso con resolverla. Y aunque hay cierta conciencia colectiva, como lo demuestran algunos titulares mediáticos recientes (Figura 24), ésta no se corresponde aún con políticas globales aceptadas y sólo actúa como denuncias aisladas. 


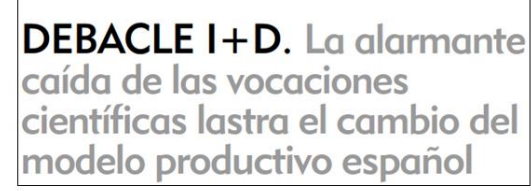

España da la espalda al gasto en I+D a pesar de la recuperación

\section{La inversión en I+D cae a la mitad y aleja a España de la vanguardia tecnológica}

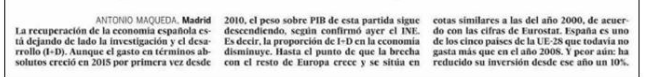

El FMI reprocha a España la escasa ayuda a la I+D privada

El director de Asuntos Fiscales del Fondo pide que se concentren más los incentivos en las nuevas empresas y eliminar las desgravaciones a la propiedad intelectual

Figura 24. Titulares sobre aspectos de la I+D+i en España (Di.

Fuente: Elaboración propia a partir de diversas fuentes mediáticas 2015-2017.

\section{La planificación estratégica de la investigación del SUE por su valor social}

La situación en la que debería estar la Universidad española en I+D+i corresponde definirla en función de los objetivos funcionales de la misma, que derivan del modelo de sociedad al que aspiramos. Si España quiere formar parte del colectivo de sociedades que sustenten su futuro en un modelo propio y autónomo, Figura 1, debe alcanzar una competitividad frente a otras que lo haga posible.

Las economías más avanzadas basan su sostenibilidad en el conocimiento y en su aplicación en procesos innovadores. Por ello requiere de personas y sistemas creativos y emprendedores, potenciadores de investigación y desarrollo y, fundamentalmente con apoyo de estos valores, de innovación. Las universidades son parte activa y responsable de que este escenario sea posible, y deben actuar sobre los primeros eslabones de la cadena para activarlo a través del círculo virtuoso de la colaboración con el resto de agentes sociales, especialmente las empresas, responsables de los procesos productivos generadores de la riqueza social.

Actuar estratégicamente requiere planificación y para planificar se debe decidir a dónde se quiere llegar. Dado que ya se ha visto donde están los que mejor lo hacen, la situación objetivo de la Universidad Española no tiene por qué ser distinta a las de los países con modelos sociales más competitivos y sostenibles, al menos en sus grandes rasgos.

Los objetivos son pues conocidos, y volviendo al símil de la Figura 23 son aquéllos que lleven al SUE del alcance limitado actual (D) al equivalente al de otros países, en los que la I+D+i les hace altamente competitivos $(H)$. Las líneas estratégicas que llevan al objetivo marcado, requieren una inversión en I+D+i suficiente, en torno al $2 \%$ del PIB, para poder entrar en el club de élite de los países, semejantes al nuestro, altamente eficaces en la aplicación del conocimiento a su estructura productiva, que a su vez estimula esta aplicación participando de forma mayoritaria, por encima del $65 \%$ en esa inversión.

Establecido el crecimiento de la innovación como elemento clave de la mejora del valor social de la función investigadora universitaria y, siendo aquella vinculada fundamentalmente al flujo de conocimiento transferido desde la universidad al tejido empresarial, es evidente que la acción más importante a acometer es la de reforzar la cultura de la transferencia de conocimiento. Y como todo proceso de transferencia requiere conectar mediante procesos coordinados al elemento difusor, universidades, y al receptor, empresas, o en su versión más amplia la sociedad en su conjunto. Es necesario tener un modelo de crecimiento apoyado en la gestión del conocimiento que: 1) potencie su generación mediante la adecuada planificación de la Investigación en universidades y otras instituciones investigadoras, alcanzando mayores cotas en el conocimiento almacenado que pueda ser inoculado (transferido) internamente en procesos de formación a las personas; 2) establezca las vías de la transferencia de ese conocimiento al entorno receptor, 
empresas y otros agentes, a través de la incorporación de las personas que lo contienen y a través de compartirlo en actividades colaborativas en procesos de investigación aplicada, innovadores o de desarrollo, y 3) garantice la aplicabilidad de ese conocimiento en procesos productivos generadores de empleo y riqueza desde las estructuras existentes, empresas, o por creación de nuevas, emprendimiento. La Figura 2425 muestra un esquema de lo que es necesario estructurar adecuadamente.

Siendo cierto que las universidades son responsables ejecutivas del Estado 1, no puedan ser ya sólo eso, sino que deben ser promotoras para que se propicien con intensidad adecuada las actividades de investigación y las que la dan continuidad. Deben hacer ver la importancia de la inversión adecuada en generación de nuevo conocimiento de forma sostenida y, para ello, hacerse partícipe en los escenarios de decisiones sobre los modelos de refuerzo de las estructuras de investigación. Deben así propiciar: procesos de discriminación en atención a la calidad y a la oportunidad de los grupos de investigación, para dar apoyo a los más competitivos a nivel internacional, potenciarles su estabilidad estructural y de recursos, tanto humanos y de equipamiento como presupuestarios, y generar el clima de estímulo para que otros grupos alcancen ese nivel; fomentar la colaboración y la interconexión público-privada en la generación de conocimiento basada en el aprovechamiento de tendencias de necesidad y oportunidad nacidas del entorno privado; potenciar la visión de los equipos humanos con formación más global en los objetivos de valor social de la investigación, sensibilizando a los investigadores con sentido innovador/emprendedor; estableciendo políticas de recursos humanos investigadores que potencien la competitividad, la formación experiencial plural y global, no endogámica, que permita recuperar y atraer talento y que fomente la creación de personal de apoyo para hacer más eficiente y eficaz el trabajo de investigación en equipo.

Pero donde las universidades, en este momento y en la situación de visión existente a nivel social global, deben abanderar claramente el necesario cambio, es en la modelización del Estado 2, que como aparece en la Figura 25, está dedicado a establecer una transferencia de conocimiento altamente eficaz. Las universidades ya no pueden esperar más a que los responsables sociales actúen adecuadamente considerando las necesidades sociales: identificando adecuadamente el papel de alto valor de la apropiada gestión del conocimiento, su generación y su transferencia; dedicándose a su planificación, más allá que de forma nominativa en sus programas, de forma efectiva y ejecutiva; apostando preferencialmente por ello en sus políticas sociales, y activando la unión en confianza entre los agentes claves para el desarrollo social. Las universidades no pueden esperar más, deben pasar a la proactividad.

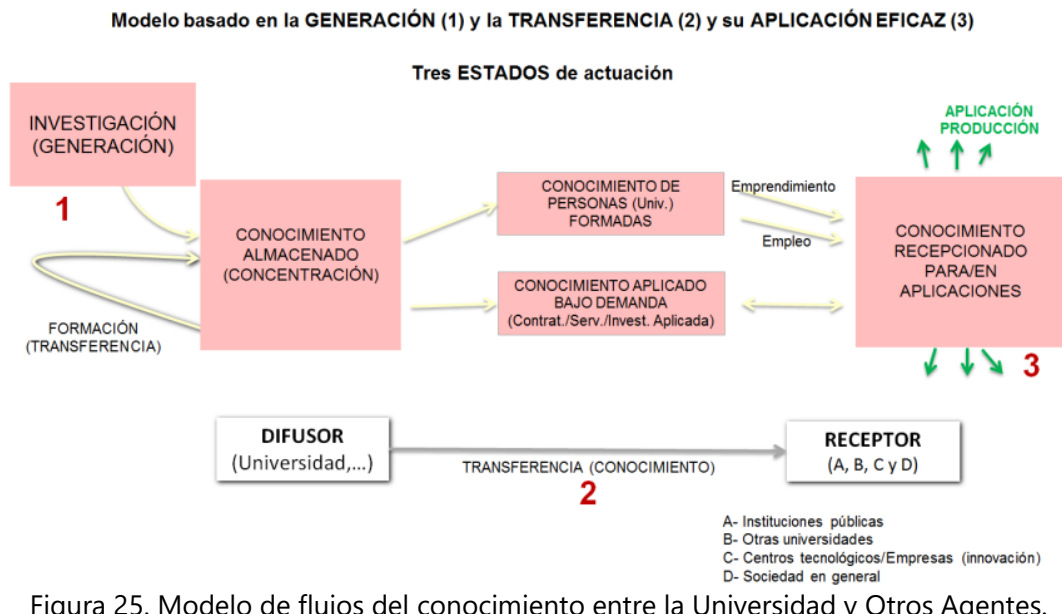

Figura 25. Modelo de flujos del conocimiento entre la Universidad y Otros Agentes. Fuente: Elaboración propia. 
Así, además de potenciar la transferencia del conocimiento desde su extremo, deben hacer que desde el otro extremo, las empresas fundamentalmente, se conecten y demanden esa transferencia, habilitando para ello canales de comunicación, de conocimiento y análisis mutuo, generadores de entornos compartidos con confianza en los otros, desde los que colaborar estrechamente, tanto en los procesos formativos en las personas, compaginando la formación en contenidos, más académica, con el de saber aplicar estos contenidos desde la experiencia de hacerlo, más experiencial-empresarial, como en los procesos de aplicación del conocimiento a fines identificados de investigación aplicada, innovación y desarrollo. Porque, tal como se aprecia en el esquema de la Figura 26, tanto las personas como los propios proyectos colaborativos que ponen en contacto personas son las vías de transferencia del conocimiento desde sus entornos de generación a los propios de su aplicación en procesos productivos.

Teniendo en cuenta el valor preponderante de las personas en el proceso de transferencia, en la planificación para potenciar ésta, además de ordenar acciones de concienciación, contacto, coordinación y colaboración con los otros agentes sociales, las universidades deben contemplar lo que deben hacer para asegurar la función de transferencia del conocimiento por cualquiera de sus vías y, fundamentalmente, reforzar aquello que no está activado o lo está de manera insuficiente. El esquema de la Figura 26 muestra las vías de acceso del nuevo conocimiento desde el entorno de las universidades al entorno empresarial, tanto a través de las personas, egresados con formación universitaria, y de los equipos investigadores, como a través de los convenios de colaboración para la ejecución de proyectos de aplicación del conocimiento a procesos novedosos o de los propios investigadores para poner sus resultados como base de nuevas empresas, spin-offs innovadoras.

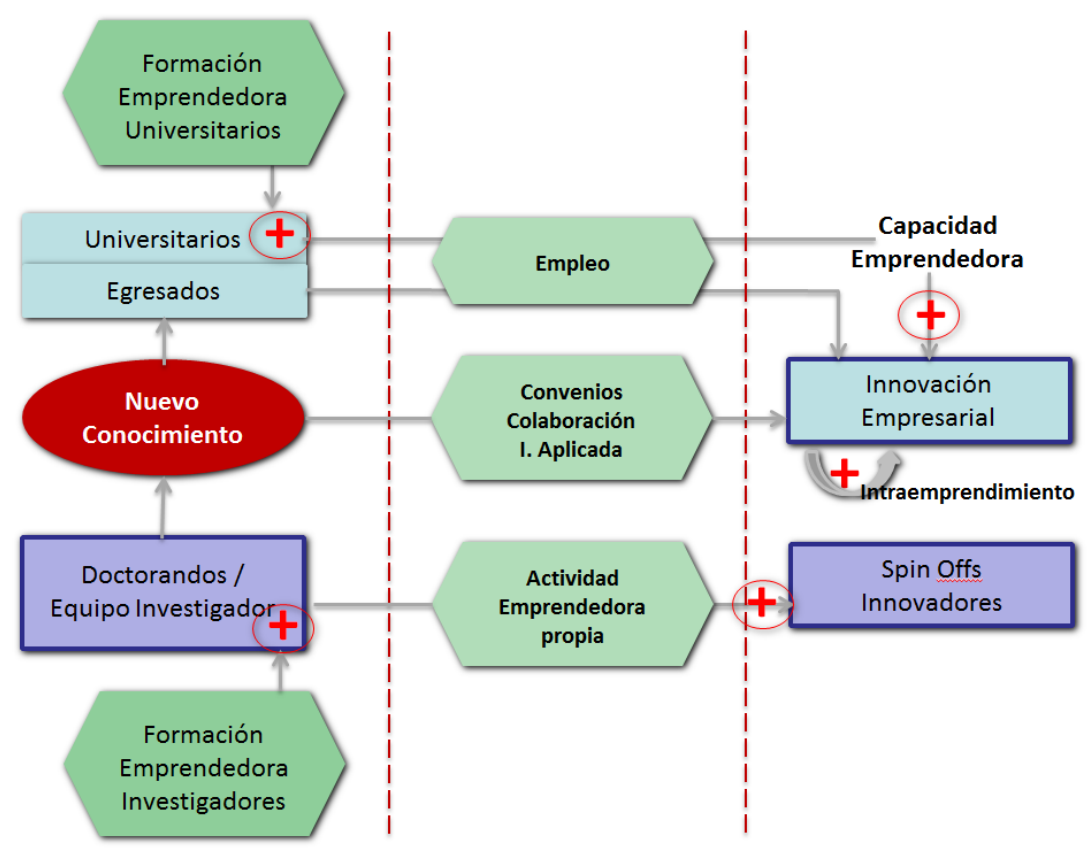

Figura 26. Esquema de transferencia del conocimiento. Acciones a potenciar. Fuente: Elaboración propia.

El propio esquema señala aquellas actividades a reforzar. La primera, imprescindible, resulta ser la potenciación de la cultura emprendedora de los universitarios en formación, a nivel de grado o posgrado, como investigadores o no, a través de programas de sensibilización y formación en todas las herramientas transversales que, potenciando su alcance, les permita aplicar su conocimiento como base de iniciativas innovadoras. 
La empleabilidad de los graduados debe crecer con su capacidad emprendedora y con ello, sean por cuenta ajena como iniciadores o apoyo a procesos innovadores o auto-empleados en iniciativas de emprendimiento propio innovador, la transferencia del conocimiento se incrementará y favorecerá la innovación empresarial. Trasladar personas con estas características al tejido productivo debe mejorar, además, la capacidad de intra-emprendimiento empresarial, cuyo déficit es importante en nuestro país $(12,13)$ y lastra la capacidad innovadora ya que no hay estímulo interno para la innovación empresarial.

Por otro lado, la sensibilización a iniciativas emprendedoras de los investigadores en formación, aportándoles la iniciación a las herramientas que necesitan para ello, comunes por otra parte a lo que necesitan para su actividad investigadora propia, se ha mostrado como potenciadora de la capacidad estructurada de las universidades para generar spin-offs propias o en colaboración con empresas. Estas nuevas empresas, al estar asentadas en el conocimiento recientemente generado en los equipos de investigación, se establecen con un alto potencial en sostenibilidad $(90 \%$ sobreviven a los 5 años) y empleabilidad (muy superior al de las nuevas empresas no universitarias consolidadas) (Igual, et al., 2015), siendo la sostenibilidad y la empleabilidad activos generadores de crecimiento y competitividad.

Esta sensibilización también es necesaria llevarla a todo el colectivo de investigadores universitarios, en todos los niveles de responsabilidad, ya que debe entenderse que contemplar la transferibilidad de los resultados de la investigación no es una pérdida de tiempo, desviadora de productividad científica inmediata, sino el sentar las bases para activar la eficacia de la acción investigadora, promotora del crecimiento a través de la transferencia, en una dirección del conocimiento para la innovación empresarial, y en sentido contrario de la demanda empresarial de nuevas colaboraciones con lo que se empieza a estimular el círculo virtuoso de relación universidad-empresa.

Cobra así sentido el potenciar las capacidades emprendedoras universitarias como factor clave desde su proactividad en la mejora de la investigación como valor social más eficaz. Máxime en un sistema como el español, al tener España unos indicadores en emprendimiento preocupantes: una tasa de actividad emprendedora en el entorno del 5,5\%, lejos del $10 \%$ en el que están las economías basadas en la innovación más emprendedoras, y un emprendimiento de calidad basado en la oportunidad menor al de éstas. Indicadores además con pérdidas importantes desde el inicio de la crisis, emparejadas temporalmente con el retroceso en inversión en I+D+i tanto pública como, fundamentalmente, empresarial privada. Ha de tenerse en cuenta, para entender la necesidad de estas acciones y su vinculación a la eficacia de la investigación, que correlacionan, siguiendo en sentido inverso el flujo de la Figura 1, la mayor competitividad con la mayor capacidad innovadora y ésta con la percepción de oportunidades de nuevos procesos de emprendimiento de calidad. Esto se aprecia en la comparación de esta percepción (Figura 27) entre países líderes innovadores, como los nórdicos en puestos preferenciales de competitividad a pesar de su menor nivel poblacional, y países innovadores moderados del sur de Europa, entre los que está España. 


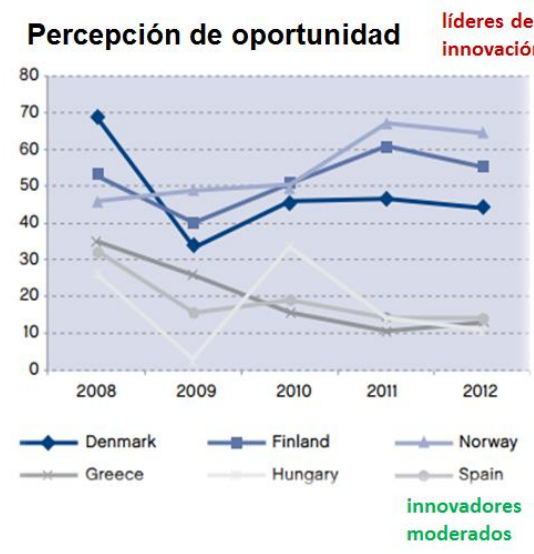

\begin{tabular}{lcccc}
\multicolumn{1}{r}{ Pais } & \multicolumn{2}{c}{$\begin{array}{c}\text { Innovación (2017) } \\
\text { Ranking }\end{array}$} & $\begin{array}{c}\text { Competice } \\
\text { Ranking }\end{array}$ & $\begin{array}{c}\text { indice } \\
\text { indicad (2017) }\end{array}$ \\
\hline Dinamarca & 6 & 58,7 & 12 & 5,35 \\
Finlandia & 8 & 58,5 & 10 & 5,44 \\
Noruega & 19 & 53,1 & 11 & 5,44 \\
\hline & & & & \\
España & 28 & 48,8 & 32 & 4,68 \\
Hungria & 39 & 41,7 & 69 & 4,20 \\
Grecia & 44 & 38,8 & 86 & 4,00 \\
\hline
\end{tabular}

Percepción de oportunidades emprendedoras

Figura 27. Relación entre percepción de oportunidades para emprender, innovación y competitividad. Fuente: GEM Global, Global Competitiveness Report 2016-17, The Global Innovation Index 2017 y elaboración propia.

Estas acciones propias del estímulo de la transferencia desde la universidad deben favorecer la situación propia del Estado 3, mostrado en la Figura 25, potenciador de la aplicación del conocimiento transferido en procesos innovadores productivos de la estructura empresarial. Aunque aparentemente fuera del marco directo de acción universitaria, la adecuada actuación de ésta en los procesos de investigación y transferencia debe servir para la mejora en la productividad y la competitividad empresarial y, con ello, para la mejora de la débil estructura empresarial española, con apenas 10.000 empresas activas en $I+D+i$, que invierten poco en ello, que son de pequeño tamaño y resultan tener baja competitividad (Figura 28) (Fundación COTEC, 2016).
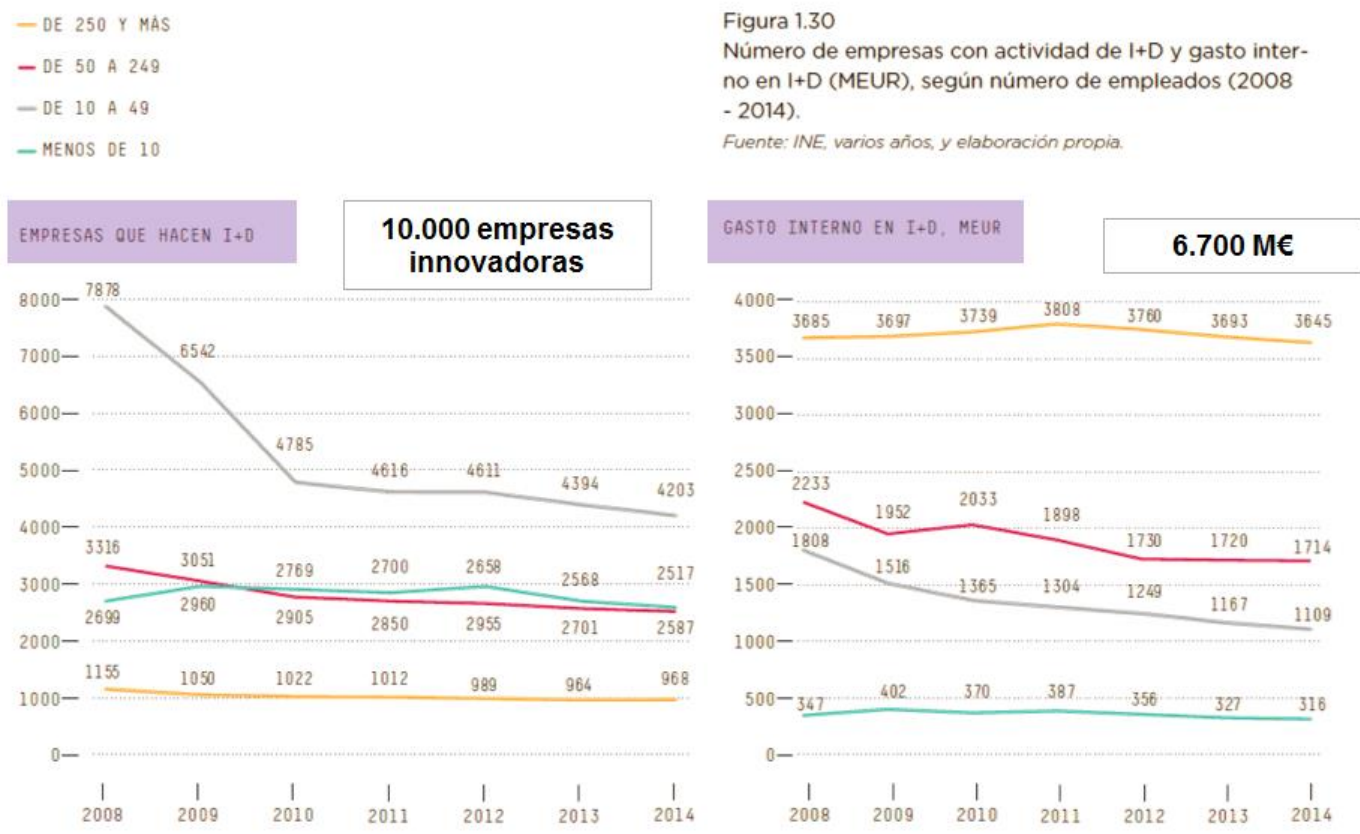

Figura 28. Evolución de la estructura empresarial innovadora y su inversión en España. Fuente: COTEC Informe 2016 


\section{Conclusiones}

Aunque nuestro SUE sea eficiente en crear ciencia, con gran número de publicaciones científicas y de una calidad más que aceptable para el presupuesto que se tiene, España es un país poco eficaz en la gestión del conocimiento puesto que no se alcanzan los objetivos que corresponden por su posición económica en cuanto a indicadores de crecimiento social. Desde esta concepción debe partir la planificación de un modelo de futuro para la I+D+i en las universidades, que defina las reformas pendientes que nos lleven de la situación actual a la establecida como objetivo.

Ya hace tiempo que se vienen ofreciendo estos modelos, como ejemplo el que presentaba la CRUE apoyándose en propuestas de COTEC (Figura 2829) (Gutiérrez-Solana y Valle, 2013; Gutiérrez-Solana, 2010), aunque no han pasado nunca a la línea ejecutiva por falta de convencimiento de todas las partes. Así que conseguir metas diferentes, ambiciosas y vinculadas al progreso de toda la sociedad, requiere acciones diferentes a las realizadas.

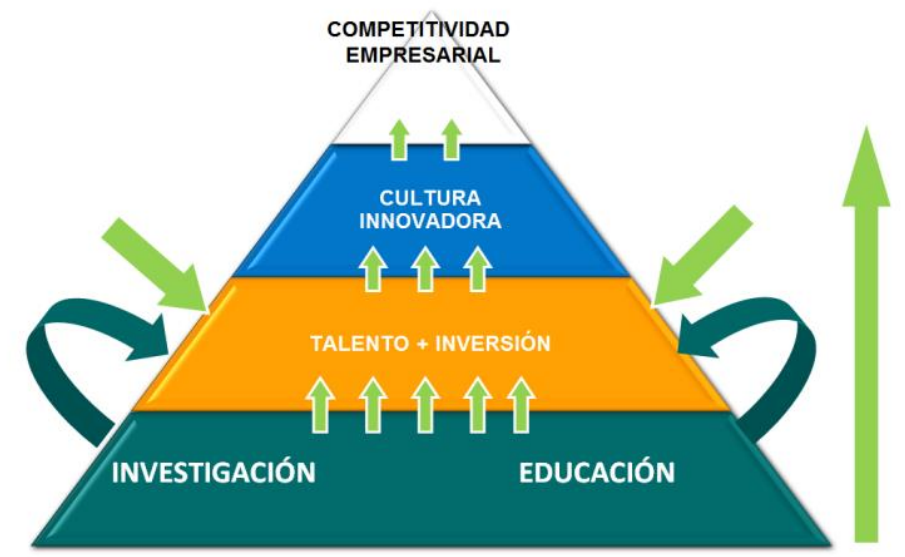

Figura 29. Modelo CRUE-COTEC para el desarrollo basado en conocimiento. Fuente: Elaboración propia.

La Universidad Española, conocedora de dónde estamos y qué deberíamos alcanzar, ambas posiciones establecidas sistemáticamente en diferentes foros, (por ejemplo, uno de los últimos (Consejería de Educación de la Junta de Castilla y León, 2017), debe propiciar, siendo proactiva en su señalamiento, las acciones que se necesitan, los actores a realizarlas, los recursos necesarios y los que se pueden disponer, así como el método y el ritmo de su ejecución. Debe hacer un cambio de estrategia que la lleve de esperar a que definan otros, fundamentalmente las empresas en su demanda de transferencia y las administraciones con las definiciones de estrategias de crecimiento apoyadas en el conocimiento, a promover las iniciativas necesarias que hagan que todos los agentes colaboren activamente. Un cambio de estrategia que haga de las Universidades- Investigadoras Universidades-Investigadoras Emprendedoras.

Se debe vincular toda la estrategia a un modelo sencillo de crecimiento social, como el mostrado en la Figura 25, basado en gestionar el conocimiento en torno a tres grandes ejes: 1 Generación de Conocimiento (1 Investigación); 2 Transferencia del Conocimiento, y 3 Aplicación Productiva del Conocimiento (2-3 Innovación). Las universidades deben ahora hacer lo necesario para que esto se produzca.

Casi está olvidada y abandonada la gran iniciativa de los Campus de Excelencia, único programa estatal con visión global para la gestión del conocimiento nacido de la investigación, generador de importantes procesos de planificación ofrecidos desde las universidades considerando las necesidades sociales, con el desarrollo social como objetivo, en un esfuerzo integrador con todos los agentes sociales. Por eso hoy, de nuevo, deben las universidades concienciar a todos los 
agentes, en particular empresas y administraciones, y promover su compromiso y su colaboración, en:

- Potenciar la investigación que permita la generación sostenida de nuevo conocimiento de calidad y aplicabilidad creciente, reforzando las estructuras y los recursos humanos y materiales para ello. Para ello deben justificar como necesidad social un mayor esfuerzo inversor en $\mathrm{I}+\mathrm{D}+\mathrm{i}$, por etapas que sean presupuestariamente asumibles y garanticen su eficacia, y favorecer un clima de transferencia adecuado que haga crecer la participación privada de esa inversión.

- Potenciar la difusión/transferencia del conocimiento, reforzando lo que nos falta, en particular, personas con capacidad emprendedora e iniciativas y estructuras innovadoras (Figura 26). Lo que exige el desarrollo de indicadores de transferencia de conocimiento adecuados y considerar la propia función formativa como una línea fundamental de la transferencia del conocimiento vehiculada a través de los estudiantes como receptores de la formación. Es necesario, por ello, escuchar bien lo que la sociedad requiere a través de sus agentes.

- Apoyar a potenciar la aplicación y explotación de lo transferido y hacerlo directamente (generación de spin-offs nacidoas de los resultados de investigación), favoreciendo el crecimiento de una estructura empresarial más innovadora y competitiva y la activación de unas administraciones más emprendedoras y flexibles.

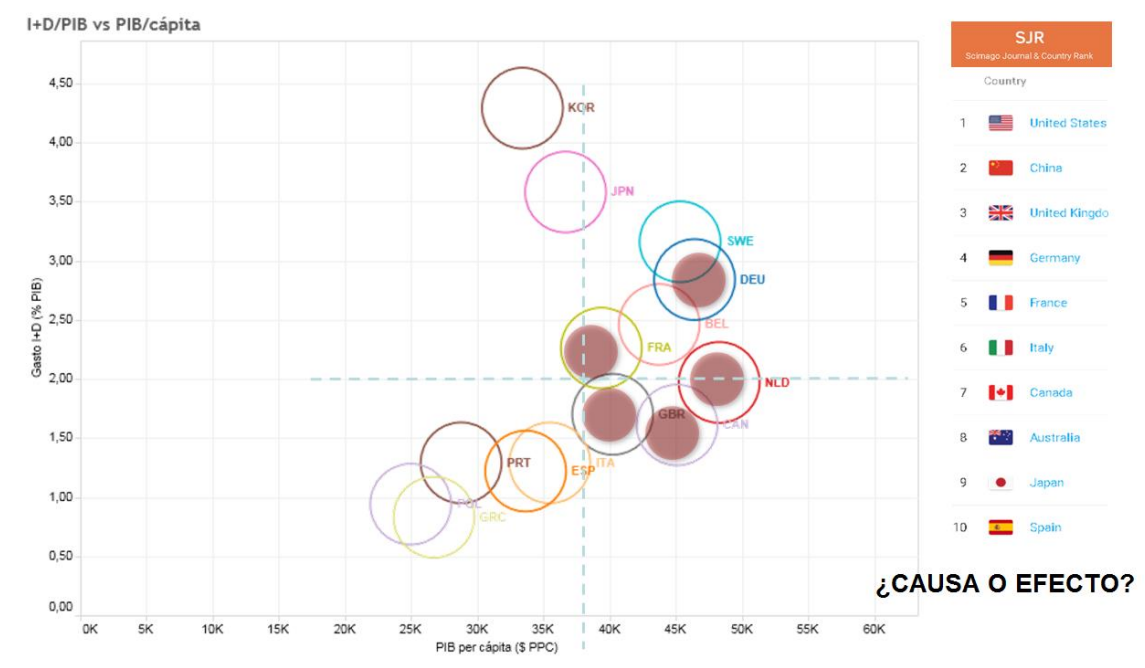

Figura 30. Relación Inversión I+D+i - Riqueza.

Fuente: COTEC Informe 2016

Para esta proactividad, las universidades deben apoyarse en informes externos absolutamente concordantes y plenamente objetivos, como el de COTEC o el de la European Research Area (European Commission, 2014; Fundación COTEC, 2016). De esta manera la investigación de las universidades tendrá el deseado y necesario reconocimiento como valor social en un activo círculo de inter-apoyo virtuoso universidad-empresas, estimulado por las administraciones públicas, con confianza entre todos y en colaboración estrecha. Así, se deberá alcanzar, tras una previa concienciación, el escalamiento de la inversión en conocimiento desde todos los agentes como soporte de un adecuado modelo de su gestión en el que se base el crecimiento económico-social. Un modelo con cuyos resultados nuestra sociedad incremente posiciones de crecimiento y desarrollo sostenibles, en similitud a cómo sucede para otros países, Figura 30, en los que se demuestra la correlación entre nivel de inversión en I+D+i y nivel de riqueza, necesaria esta para crear bienestar social. 


\section{Referencias bibliográficas}

Alianza 4 Universidades (2016). Informe IUNE 2016. Actividad Investigadora de la Universidad Española.

Centro Internacional Santander Emprendimiento (2016). Emprendimiento corporativo en España: Situación y claves de la colaboración entre empresas y emprendedores para innovar y ser más competitivas.

Centro Internacional Santander Emprendimiento (2016). Global Entrepreneurship Monitor: Informe GEM España.

Consejería de Educación de la Junta de Castilla y León (2017). Reformas Urgentes del Sistema Universitario Español.

Cornell INSEAD WIPO (2017). The Global Innovation Index 2017. Innovation Feeding the World.

CRUE Universidades Españolas (2015). La Universidad Española en cifras 2014-2015.

European Commission, European Research Area (2014). ERAC Peer Review of Spanish Research and Innovation System - Final Report.

Fundación Conocimiento y Desarrollo (2015). Informe CYD.

Fundación COTEC (2016). Decálogo COTEC para la innovación.

Fundación COTEC (2016). Informe COTEC 2016.

Gutiérrez-Solana, F. en V Edición Premios Universidad-Empresa. Madrid, Noviembre 2010.

Gutiérrez-Solana, F. y Valle, A. (2013). Los avances del Sistema Universitario Español: Medir sus resultados. En Climent, V.; Michavila, F. y Ripollés, M. (Eds.), Los Rankings Universitarios, mitos y realidades (pp. 23-41). Madrid: Tecnos.

Igual, J.F.; Meliá, E.; Villalonga, I. y Carnicer, M.P. (2015). El emprendimiento en el sistema universitario. El caso de las Universidades de la ciudad de Valencia. Santander: Editorial de la Universidad de Cantabria.

Pastor, J.M. y Peraita, C. (2012). La Contribución socioeconómica del Sistema Universitario Español. Madrid: Ministerio de Educación, Cultura y Deporte, Secretaría General de Universidades.

SJR. Scimago Journal \& Country Rank (2016). http://www.scimagojr.com/

Thomson Reuters Web of Science (2016). http://apps.webofknowledge.com

World Economic Forum (2016). Global Competitiveness Report 2016-17. 
